\title{
The frog vestibular system as a model for lesion-induced plasticity: basic neural principles and implications for posture control
}

\author{
François M. Lambert ${ }^{1}$ and Hans Straka ${ }^{2}$ * \\ 1 Department of Physiology, University of Oslo, Oslo, Norway \\ ${ }^{2}$ Biocenter-Martinsried, Department Biology II, Ludwig-Maximilians-University Munich, Planegg, Germany
}

\section{Edited by:}

Kenna Peusner, George Washington University, USA

\section{Reviewed by:}

Kenna Peusner, George Washington University, USA

Ian S. Curthoys, University of Sydney, Australia

\section{*Correspondence:}

Hans Straka, Biocenter-Martinsried,

Department Biology II,

Ludwig-Maximilians-University

Munich, Grosshaderner Strasse 2,

82152 Planegg, Germany.

e-mail: straka@lmu.de
Studies of behavioral consequences after unilateral labyrinthectomy have a long tradition in the quest of determining rules and limitations of the central nervous system (CNS) to exert plastic changes that assist the recuperation from the loss of sensory inputs. Frogs were among the first animal models to illustrate general principles of regenerative capacity and reorganizational neural flexibility after a vestibular lesion. The continuous successful use of the latter animals is in part based on the easy access and identifiability of nerve branches to inner ear organs for surgical intervention, the possibility to employ whole brain preparations for in vitro studies and the limited degree of freedom of postural reflexes for quantification of behavioral impairments and subsequent improvements. Major discoveries that increased the knowledge of post-lesional reactive mechanisms in the CNS include alterations in vestibular commissural signal processing and activation of cooperative changes in excitatory and inhibitory inputs to disfacilitated neurons. Moreover, the observed increase of synaptic efficacy in propriospinal circuits illustrates the importance of limb proprioceptive inputs for postural recovery. Accumulated evidence suggests that the lesion-induced neural plasticity is not a goal-directed process that aims toward a meaningful restoration of vestibular reflexes but rather attempts a survival of those neurons that have lost their excitatory inputs. Accordingly, the reaction mechanism causes an improvement of some components but also a deterioration of other aspects as seen by spatio-temporally inappropriate vestibulo-motor responses, similar to the consequences of plasticity processes in various sensory systems and species. The generality of the findings indicate that frogs continue to form a highly amenable vertebrate model system for exploring molecular and physiological events during cellular and network reorganization after a loss of vestibular function.

Keywords: utricle, vestibular, spinal cord, skeletal deformation, proprioception, semicircular canals, posture, scoliosis

\section{INTRODUCTION}

Bilateral vestibular afferent signals from semicircular canal and otolith organs are essential for the stabilization of gaze, control of posture and locomotion, as well as for cognitive aspects of balance, self-orientation, spatial navigation, and vegetative homeostasis (Olabi et al., 2009; Dutia, 2010; Smith et al., 2010). Damage to the inner ear or to the vestibular nerve, through accident, disease, or intended experimental manipulations results in a complex syndrome of static (in the absence of body motion) and dynamic (during body motion) ocular motor, postural and cognitive deficits. Initial static deficits such as the postural asymmetry and spontaneous nystagmus after unilateral labyrinthectomy (UL) disappear over time. This behavioral recovery is generally assumed to represent the consequence of a process called "vestibular compensation" that differs in its extent and time course for different symptoms as well as for different vertebrate species as summarized by a large number of classical papers (e.g., Smith and Curthoys, 1989; Dieringer, 1995; Vibert et al., 1997, 1999;
Curthoys and Halmagyi, 1999; Curthoys, 2000; Darlington et al., 2002) as well as by more recent reviews (e.g., Cullen et al., 2009; Olabi et al., 2009; Shao et al., 2009; Dutia, 2010; Smith et al., 2010). Since the vestibular epithelium does not regenerate after a peripheral lesion and removal of the endorgans in postembryonic animals, the subsequent progressive disappearance of the initial behavioral symptoms is attributed to plasticity processes in the central nervous system (CNS) including various areas such as the vestibular nuclei, cerebellum, spinal cord, and cortical structures (Dutia, 2010). In fact, results from an increasing number of studies suggest that different forms of neural plasticity occur simultaneously as well as consecutively at multiple sites in the brain and spinal cord, compatible with the notion of "vestibular compensation" as a multiple, distributed process (Llinás and Walton, 1979).

The unilateral loss of vestibular sensory inputs causes an imbalanced activity along central pathways and in circuits that are involved in vestibular signal processing. As a consequence, 
this imbalance triggers objective behavioral symptoms, such as spontaneous nystagmus, postural asymmetry, and gaze instability but also subjective illusions such as vertigo (Dutia, 2010). The asymmetric posture is one of the most prominent static deficits and its time course of recovery is often correlated with the progression and extent of CNS plasticity (Dieringer, 1995; Curthoys, 2000). In contrast to dynamic deficits such as direction-specific impaired vestibulo-ocular reflexes (VOR), which show only poor recovery, static deficits, including asymmetric limb and body positions, recover almost entirely and only reappear in chronic animals under certain conditions (Dieringer, 1995, 2003).

The removal of particular vestibular endorgans causes postural deficits that correlate with the loss of one or more semicircular canal or otolith organs, respectively (Dieringer, 1995). Depending on the absence of specific combinations of endorgans, different static and dynamic deficits predominate. The various pathologies are caused by the combinatorial accumulation of direct effects following the loss of particular labyrinthine organs and secondary effects that are triggered by the postural asymmetry. The resulting deficits after a complete UL are similar in all tetrapods studied so far (Dieringer, 1995). However, some species-specific variations in the extent of the deficiencies exist and are likely correlated with particular skeletal configurations that mainly concern the length and curvature of the neck and the articulation of the head (Vidal et al., 1998).

Since the experiments by Precht et al. (1966) in cat, many studies attempted to explain and link changes at cellular and network levels with improvements of the behavioral symptoms after a peripheral vestibular lesion. One of the key ideas has been the notion of "vestibular compensation" as a process that consequently leads to a recovery of the initial behavioral deficits. However, this view of a goal-directed process is contradicted by the fact that a number of symptoms, in particular deficits in the dynamic components of vestibular reflexes, show no recovery, even many years after the lesion (Hamann et al., 1998). Moreover, the observed improvement of some of the initial deficits is no proof that mechanisms are at work that aim toward a restoration of normal function by a driven readjustment of cellular and network properties through specific sensory or intrinsic substitution processes (Dieringer, 2003).

Most plastic neural changes were for obvious reasons observed in the bilateral central vestibular nuclei and include altered intrinsic membrane and discharge properties of second-order vestibular neurons ( $2^{\circ} \mathrm{VN}$; Beraneck et al., 2003, 2004; Shao et al., 2009), differential modifications of $\mathrm{GABA}_{\mathrm{B}}$ receptor-mediated vestibular commissural inhibition (Bergquist et al., 2008), increased efficacy of NMDA receptor-mediated components in ipsilesional $2^{\circ} \mathrm{VN}$ (Knöpfel, 1987; see Smith and Darlington, 1997) and neurogenesis in the ipsilesional vestibular nucleus (Tighilet et al., 2007). These mostly molecular and cellular changes are supplemented by a more global process of what is called sensory substitution by other body motion-related signals such as visual or proprioceptive signals (see Brandt et al., 1997; Curthoys, 2000; Darlington and Smith, 2000) as well as by contributions that depend on intact cerebellar circuitries (Kitahara et al., 1997; Cullen et al., 2009; Dutia, 2010).

The number of reported post-lesional alterations at molecular, cellular, network, and behavioral levels is paralleled by an equally large spectrum of employed vertebrate models that ranges from fish to mammals (Dieringer, 1995). Instead of adding another general review on plasticity processes in the vertebrate CNS after UL to the multitude of existing comprehensive publications, this review will mainly focus on general vertebrate principles of vestibular lesion-induced behavioral and neural plasticity discovered in frog and aims to extend the classical review by Dieringer (1995) by emphasizing more recent findings and adding new interpretations of existing data.

Frogs were among the first species in which the consequences of a unilateral labyrinthine lesion (Goltz, 1870; Ewald, 1892; Laudenbach, 1899) or pharmacological elimination of labyrinthine function (Thauer and Peters, 1935) have been studied and a number of basic concepts of post-lesional plasticity in the vestibular system of vertebrates have been described in this animal model (e.g., Dieringer and Precht, 1977; Straka and Dieringer, 1995; Goto et al., 2000). The discovery of these general reaction principles was facilitated by a number of advantages of frogs, such as the easy access to bilateral vestibular endorgans for experimental manipulations (Figures 1A,B; Goto et al., 2002), the well-determined spatially specific convergence of afferent semicircular canal and otolith inputs in individual $2^{\circ} \mathrm{VN}$ (Straka et al., 2002) or the possibility to use an isolated whole brain preparation for probing cellular and network physiology in vitro (Cochran et al., 1987). The relatively small volume of $\sim 6 \mathrm{~mm} \times 2 \mathrm{~mm} \times 1.5 \mathrm{~mm}$ of the entire brainstem along with the possibility to work at a temperature of $14-16^{\circ} \mathrm{C}$ in these poikilothermic animals allows a utilization of the latter preparation for electrophysiological recordings without noticeable deterioration of up to 7 days (see Straka and Dieringer, 2004). Even though, a distinction of the vestibular nucleus into the different classical subnuclei on the basis of cytoarchitectural features is difficult in frog, it is possible to correlate stereotactically defined positions of recorded central vestibular neurons with the intrinsic hindbrain segmental organization (Straka et al., 2003) and thus with the rhombomeric framework in these animals (Straka et al., 2001). With respect to the determination of plasticity events, this allows a sampling of larger numbers of neurons throughout the entire vestibular nuclei with reference to fixed external landmarks in the attempt to obtain a representative overview of potential changes after UL that can be assigned to particular functional subgroups. The combination of all these advantages forms an excellent basis for the use of frogs as a model to study questions related to post-lesional vestibular plasticity. In the following, particular aspects of behavioral and neural changes after UL will be highlighted by illustrating several key results that allowed deducing basic patterns and conceptual principles that also govern the behavioral recovery from a vestibular loss or dysfunction in other vertebrate species, including humans.

\section{ANATOMICAL ARRANGEMENT OF PERIPHERAL LABYRINTHINE ENDORGANS AND CONSEQUENCES OF SURGICAL MANIPULATIONS}

Amphibian labyrinthine endorgans consist of three semicircular canals, three macula organs (utricle, lagena, and saccule), and two papillary organs (basilar papilla and amphibian papilla) on each side (for review see Straka and Dieringer, 2004). At variance with mammals, these sensory organs are not located in a bony labyrinth 


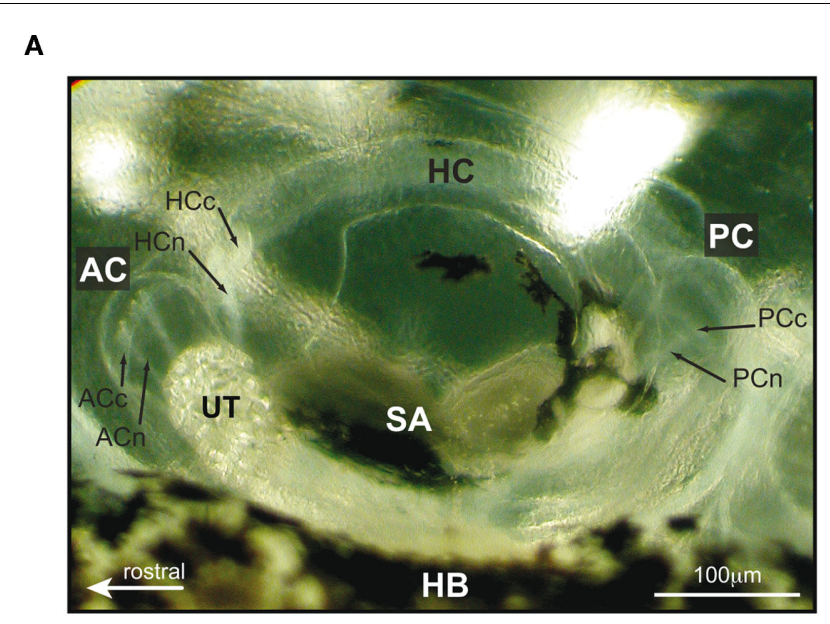

B

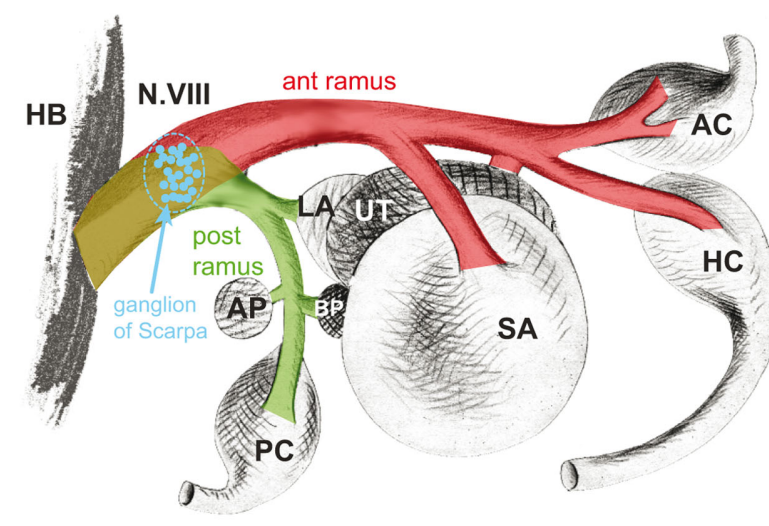

FIGURE 1 | Morphological organization and afferent innervation of labyrinthine endorgans in amphibians. (A) Top view of the otic capsule with semicircular canal and otolith organs of a stage 53 Xenopus laevis tadpole. (B) Color-coded schematic drawing of the VIIIth nerve, ganglion of Scarpa (blue), separation into an anterior (ant ramus, red) and posterior (post ramus, green) branch, and innervations of individual labyrinthine endorgans in a ranid frog. $\mathrm{HC}, \mathrm{PC}, \mathrm{AC}$, horizontal, posterior, and anterior vertical canal; HCn, HCc, PCn PCc, ACn, ACc, nerve branches ( $n$ ) innervating the cupula (c) of the semicircular canal organs, respectively; $\mathrm{BP}$, basal papilla; AP, amphibian papilla; SA, saccule; UT, utricle; HB, hindbrain; ant/post ramus, anterior/posterior VIIIth nerve branch; modified and adapted from Goto et al. (2002).

but in a relatively spacious cartilaginous bulla with all organs plainly visible under the microscope (Figure 1A). This anatomical particularity is an enormous advantage for all experimental manipulations and facilitates the transection of specific nerve branches and/or the removal of individual endorgans under direct visual control. As in all other vertebrates, labyrinthine organs are innervated by afferent fibers of the VIIIth nerve, which, at the level of Scarpa's ganglion, form an anterior (ramus anterior) and a posterior branch (ramus posterior) before entering the otic capsule (Figure 1B; de Burlet, 1929). The anterior branch innervates the horizontal and the anterior vertical semicircular canal, the utricle and the saccule, while the posterior branch innervates the posterior vertical semicircular canal, the lagena, as well as the basilar and amphibian papillary organ (Figure 1B), with the latter two organs being sensitive to air-borne sound (Lewis and Li, 1975). With the exception of the saccular innervation by fibers in the anterior branch as well as by additional variable contributions of afferent fibers in the posterior branch in some species (e.g., Xenopus laevis), this organizational scheme essentially applies to all amphibians (de Burlet, 1929). In frog, the largest numbers of afferent fibers innervate the utricle $(\sim 4000)$, whereas fewer fibers supply the lagena $(\sim 2000)$, the semicircular canals or the saccule (each up to 1500), respectively (Dunn, 1978; Honrubia et al., 1989).

The three semicircular canals on one side in frogs are oriented approximately perpendicular with respect to each other and form functional pairs with their respective coplanar partner canal on the other side (Blanks and Precht, 1976). Morphometric details of frog semicircular canals are similar to those of other vertebrates, although some differences in duct diameter, curvature, and dimensions of the ampullar cristae exist (Ramprashad et al., 1986). The utricle is largely oriented in the plane of the horizontal semicircular canals (Rohregger and Dieringer, 2002) and sensitive to linear acceleration and changes of the head position with respect to the earth gravitational vector (Blanks and Precht, 1976). As a complement, the two other amphibian otolith organs are oriented approximately vertically. While a clear graviceptive function is demonstrated for the lagena (Caston et al., 1977), a sensitivity of the saccule for changes in head position has been reported in some studies (Gallé and Clemens, 1973; Lannou and Cazin, 1976) but not in others (Ashcroft and Hallpike, 1934).

At variance with this inconclusive role of the saccule in detecting static and/or dynamic body position in space, there is clear evidence that this latter otolith organ is highly sensitive to substrate vibration (Koyama et al., 1982) and for a central connection with midbrain auditory centers (see Straka and Dieringer, 2004). Such a sensitivity to vibrational stimuli, however, is not restricted to the saccule but has been reported to varying degrees for lagena (Cortopassi and Lewis, 1996; Harada et al., 2001) and utricular afferent fibers (Jørgensen and Christensen-Dalsgaard, 1991) and is likely due to the presence of particular hair cell types along the striola (Baird and Lewis, 1986). Thus, all three otolith organs might have a dual function in frog, even though to differential extents. While the utricle and the lagena mainly serve as gravitoinertia-sensitive organs, the saccule is a highly sensitive detector for substrate vibration. This differential organization with respect to their sensory sensitivity and their major functional role is important, when interpreting potential contributions of the lagena and the saccule to deficits in vestibulo-motor responses after an ablation.

Unilateral ablation and removal of all vestibular endorgans causes a number of static and dynamic behavioral deficits in frog as in all other vertebrates. The most obvious symptom is a characteristic asymmetric posture of head, body, and limbs (Figure 2A), as first described by Goltz (1870) and Ewald (1892). The principal behavioral deficit is a tonic head roll tilt toward the ipsilesional side with a magnitude of up to $\sim 45^{\circ}$ that is caused by an asymmetric activation of bilateral neck muscles (Dieringer, 1995). This tonic head roll along the longitudinal body axis is accompanied by asymmetric limb positions that consist of flexed and extended limbs on the ipsi- and contralesional side, respectively (colored limbs in Figure 2A). However, the asymmetric limb position appears to be a secondary effect and a consequence of the lesion-induced 


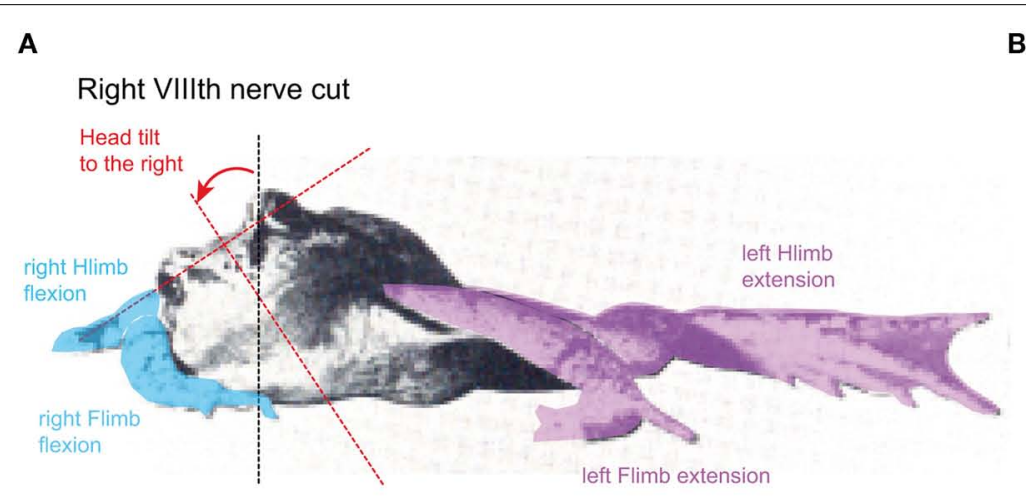

\section{B}

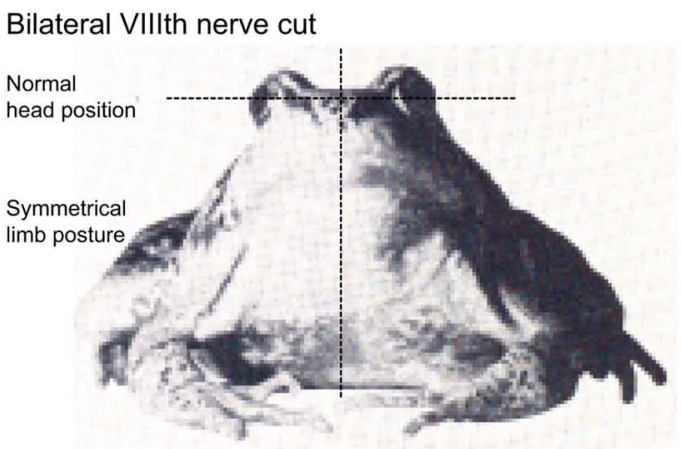

C

D
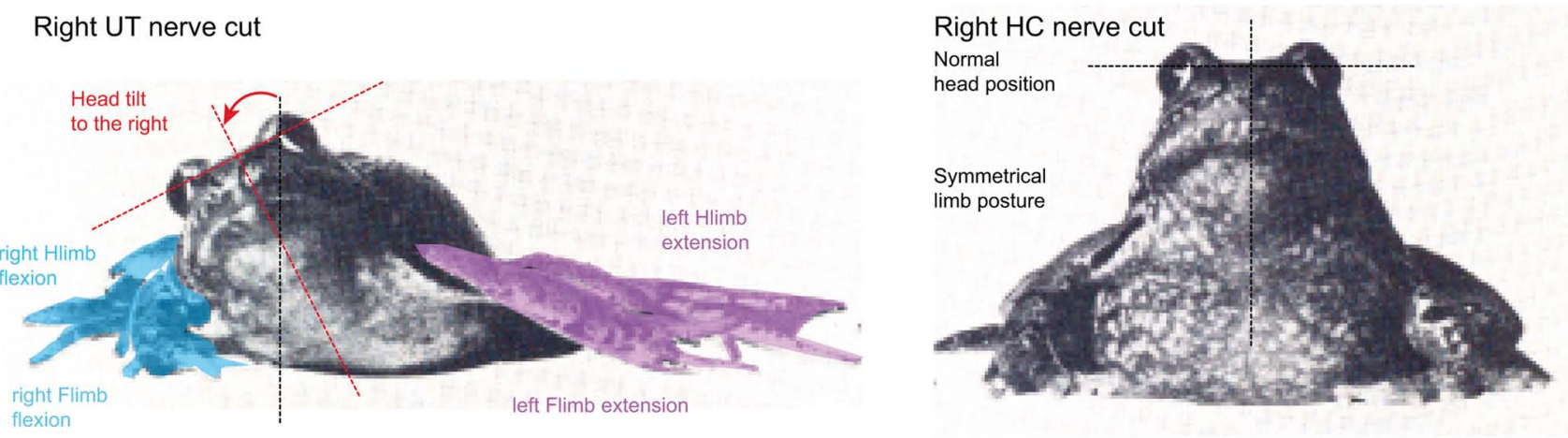

FIGURE 2 | Different postural consequences after selective lesion of the VIIIth nerve in adult grass frog. (A-D) Induction of an ipsiversive head roll tilt and ipsilesional flexed (blue) and contralesional extended (violet) fore- and hindlimbs after unilateral section of the entire VIIIth nerve (A) or the utricular
(UT) nerve branch on the right side (C); absence of postural deficits after a bilateral section of the VIIIth nerve (B) or of one horizontal semicircular canal nerve (D). Hlimb, hindlimb; Flimb, forelimb. Modified and adapted from Precht and Dieringer (1985). torque of the neck, rather than an immediate consequence of the removal of one labyrinth (de Kleijn, 1914). This notion is supported by results of a more recent study where a weight was mounted eccentrically on the head of a frog (Straka and Dieringer, 1995). In the presence of the weight, a normal head posture was maintained against the neck torque and the forelimbs assumed a similar, although somewhat less asymmetric posture as seen after UL. The asymmetric UL-induced posture is complemented by a tonic asymmetric deviation of the eyes toward the side of the lesion, even though its degree is rather marginal compatible with the relatively small ocular motor range of adult frogs (Dieringer and Precht, 1982).

An attempt to determine the contribution of the different vestibular endorgans to static and dynamic postural reflexes in frog was made by several extensive, almost heroic, series of lesion experiments (McNally and Tait, 1925, 1933; Tait and McNally, 1934; MacNaughton and McNally, 1946). These studies describe in great detail the differential functional contributions of individual semicircular canal and otolith organs to the maintenance of a normal posture in frogs, by interpreting the behavioral consequences of postural deficits after uni- or bilateral removal of different combinations of endorgans. The observed postural asymmetry after the loss of one labyrinth (Figure $2 \mathrm{~A}$ ) is essentially caused by a unilateral removal of the utricle (Figure 2C), since bilateral section of the VIIIth nerve (Figure 2B) or lesion of one horizontal semicircular canal (Figure 2D) does not cause the obvious tonic postural deficits (Tait and McNally, 1934). A similar postural asymmetry, although temporally more transient, could be evoked by a unilateral lesion of the anterior and posterior vertical semicircular canals that caused a slight head roll tilt $\left(10-15^{\circ}\right)$ toward the ipsilesional side (McNally and Tait, 1933). However, as the former authors emphasized, the animals could correct the residual head deviation at any time to resume a symmetric posture. This suggests that the absence of the two vertical semicircular canals on one side essentially causes a dynamic deficit that corresponds in its direction to the loss of the utricle on the same side but becomes apparent only during passively induced or self-motion (Dieringer, 1995).

While tonic behavioral deficits were also absent after a unilateral horizontal canal lesion (Figure 2D), the dynamics of gazestabilizing compensatory eye/head movements during vertical axis rotation in these animals was severely impaired (Gribenski, 1963; Precht and Dieringer, 1985). The absence of horizontal semicircular canal signals during rotation in the ipsilesional direction in light are substituted by saccadic head movements that appear to depend on head velocity-related proprioceptive reafferent inputs (Dieringer, 1988). These head saccades are accompanied by smaller ocular quick phases and are still present after a bilateral section of the horizontal canal nerves or after removal of 
both labyrinths, suggesting a non-vestibular origin. Finally, unilateral ablation of the lagena provokes a slight upward tilt of the head on the ipsilesional side, while a bilateral lesion has little effect on the posture, although it severely impairs the righting reflex from a supine position (MacNaughton and McNally, 1946). In contrast, uni- or bilateral lesion of the saccular nerve neither disturbs posture nor deteriorates locomotor performance (Laudenbach, 1899; McNally and Tait, 1925). This is compatible with the well-established substrate vibration sensitivity (see above) of the saccule and indicates that this organ in frog has no detectable role in vestibular function.

In summary, the principal static postural deficit after UL in frog is a head roll tilt toward the ipsilesional side. The absence of an additional tonic head deviation in the horizontal plane as observed in, e.g., guinea pigs is related to differences in the skeletal geometry of the cervical region (de Waele et al., 1989). In fact, the short neck in frogs likely prevents a major deviation in the horizontal plane after ablation of one labyrinth at variance with the situation in most other vertebrates (Graf et al., 1995). With the exception of the latter species-specific particularity, primary and secondary consequences of a labyrinthine lesion in frogs on head/body/limb position complies with the presumed general principles of vestibular influences on skeletal geometry and postural behavior (Vidal et al., 1998).

\section{CONSEOUENCES OF PRE- AND POSTGANGLIONIC LESIONS ON VESTIBULAR NERVE AFFERENTS}

The surgical manipulations that were used for studying neural and behavioral consequences of a unilateral loss of vestibular sensation usually consist of a destruction and removal of the labyrinth (labyrinthectomy) and/or of cutting the vestibular nerve, with or without removal of Scarpa's ganglion (vestibular neurectomy; see Dieringer, 1995, 2003). In studies that report on different aspects following the loss of one labyrinth in frog, the vestibular nerve was sectioned either proximal or distal to Scarpa's ganglion (Figures 3A,B) and semicircular canal and otolith organs were removed (Kunkel and Dieringer, 1994). However, independent of conservation (preganglionic lesion; Figure 3A) or removal of the ganglion (postganglionic lesion; Figure 3B), the magnitude of the induced behavioral asymmetry of body posture and limb position was similar (Kunkel and Dieringer, 1994). This is not too surprising since both experimental conditions eliminate the vestibular nerve afferent resting discharge, which is the major excitatory drive of central vestibular neurons, thereby causing an imbalanced activity on both sides (Dieringer, 1995). However, the anatomical consequences of the two types of interventions in frog differ considerably.

After a postganglionic lesion, axons and central terminals of vestibular nerve afferents start degenerating almost immediately after the lesion as visualized by a specific silver impregnation method (Figure 3D) and have entirely disappeared a few weeks later (Kunkel and Dieringer, 1994). In contrast to this degeneration, vestibular afferents survive after a preganglionic lesion (Kunkel and Dieringer, 1994) as seen by the absence of degenerating fibers (Figure 3C). This is similar to the situation in cat, where a large part of vestibular nerve afferents survives at least for 1 year after a UL that spared the vestibular ganglion (Gacek and Schoonmaker, 1997) but disappears when the ganglion is destroyed (Schuhknecht, 1982). Thus, the absence or presence of afferent degeneration after a pre- versus postganglionic lesion appears to be a general reaction principle. The surviving afferent fibers after a preganglionic lesion in frog even maintain the synaptic connectivity with their target neurons in the vestibular nuclei since electrical stimulation of the stump of the anatomically persisting ipsilesional VIIIth nerve 2 month after the lesion evokes excitatory responses in $2^{\circ} \mathrm{VN}$ (Figures 3E,F) with similar magnitudes compared to controls (Kunkel and Dieringer, 1994; Goto et al., 2001).

\section{TIME COURSE OF POSTURAL RECOVERY}

Static, in contrast to dynamic symptoms after UL recover almost completely over time, although with different species-specific time courses (see Dieringer, 1995; Straka et al., 2005). In grass frogs (Rana temporaria), the asymmetric posture after UL consists of a head roll tilt to the operated side of up to $45^{\circ}$ and, as a secondary consequence, bilateral asymmetrically flexed and extended limb positions (Figure 2A). The angle of the head deviation normalizes with an asymptotic time course (Figures $4 \mathbf{A}, \mathbf{B}$ ) and is more or less complete after about 2 month (Kolb, 1955; Bienhold and Flohr, 1980; Kunkel and Dieringer, 1994). Despite the considerable morphological consequences for the survival of afferent fibers after pre- versus postganglionic lesions (Kunkel and Dieringer, 1994), there appears to be neither a major difference in the extent of postural deficits nor in the time course of the recovery whether Scarpa's ganglion is spared or not. However, under both conditions, a normal posture is only attained during static positions of the animal, while dynamic positional changes, arousing stimuli or locomotor activity is often accompanied by a decompensation and reappearance of the acute postural syndrome (Dieringer, 1995).

Additional removal of the remaining intact labyrinth at different time intervals after the first lesion causes the classical Bechterew-symptom that is a mirror image of the behavioral deficit induced by the first lesion (von Bechterew, 1883). In grass frogs, the minimal time interval for the induction of the Bechterew-symptom is 5 days (Dieringer and Precht, 1981) and is followed by a postural normalization that progresses more slowly and is less complete compared to the reaction after the first lesion (Kolb, 1955). The mirror image-like head deviation after the delayed, second lesion has been interpreted as evidence for a CNS plasticity, since simultaneous removal of both labyrinths fails to provoke a postural syndrome (Dieringer and Precht, 1981).

Even though most experiments in amphibians have been conducted on grass frogs, a comparison with results from water frogs (R. esculenta) is of particular importance for understanding the mechanisms that are at play during the postural recovery process. Interestingly, water frogs exhibit a postural normalization after UL that is incomplete with a residual head deviation of $5-10^{\circ}$ (Figure 4A; Kolb, 1955). This difference between water and grass frogs might be related to particularities in the life style of the two anuran species. The more aquatic water frogs mostly float in water, which limits the use of body-weight-supporting limb proprioceptive signals as potential source for a sensory substitution of absent vestibular signals (see below). In contrast, the terrestrial 


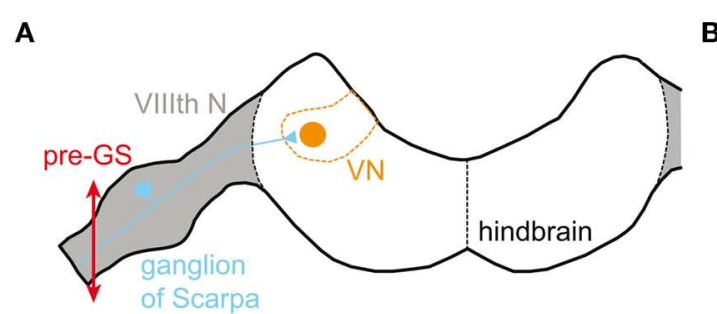

C

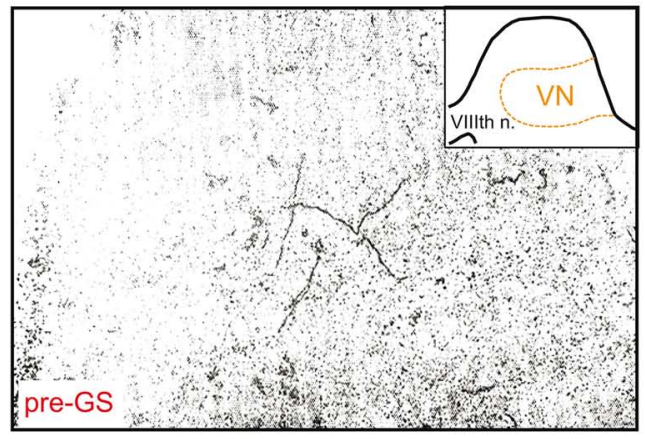

E

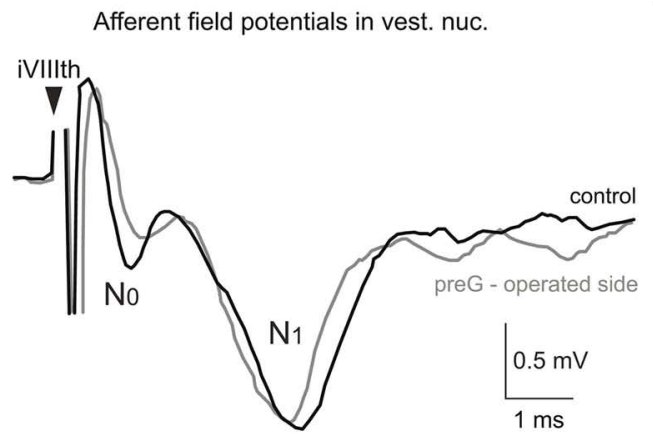

D

$\mathbf{F}$
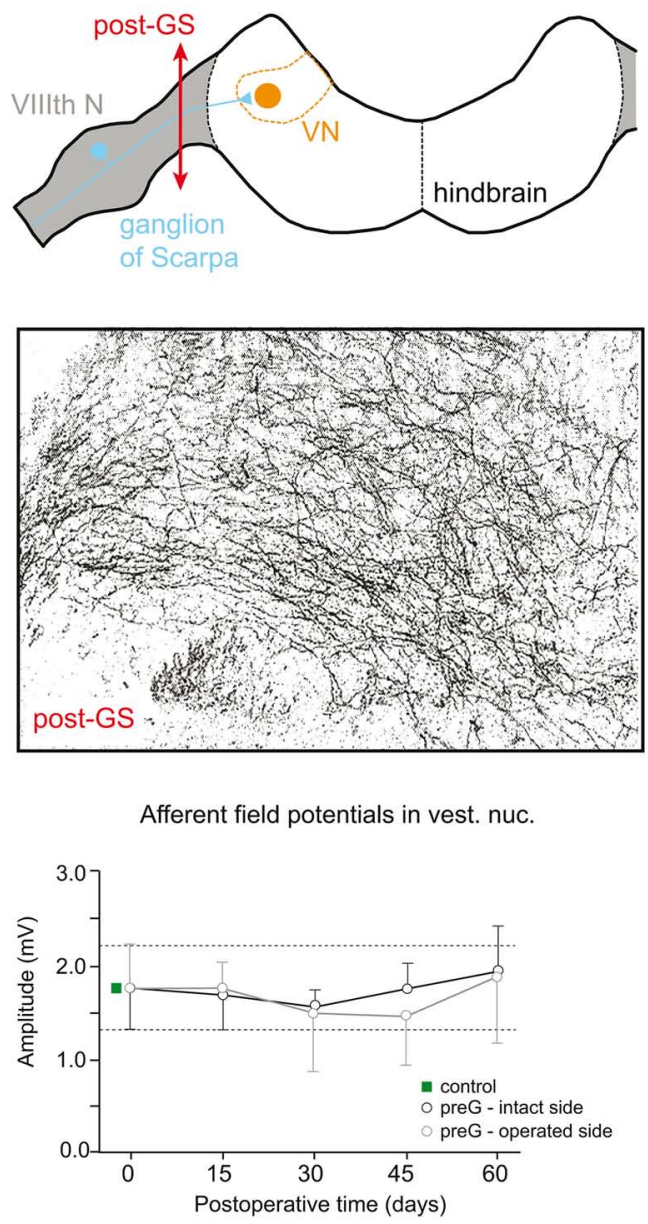

vestibular nerve afferent fibers were visualized by a silver impregnation method. (E,F) Pre- $\left(\mathrm{N}_{0}\right)$ and postsynaptic components $\left(\mathrm{N}_{1}\right)$ of ipsilateral VIIIth nerve-evoked afferent field potentials (E) recorded in the $\mathrm{VN}$ on the intact and operated side of chronic UL frogs with a pre-GS; mean amplitudes of the $\mathrm{N}_{1}$ afferent field potential component, recorded on the intact (control) and operated side at different survival periods after a pre-GS (F); modified and adapted from Straka et al. (1993) and Kunkel and Dieringer (1994). life style of grass frogs or toads and the resulting availability of limb proprioceptive sensory signals favor a more or less complete behavioral normalization (Straka and Dieringer, 1995). Accordingly, the latter sensory signals might form the relevant reference frame that allows a reestablishment of a normal, symmetric body position in space. This interpretation is corroborated by results of experiments in grass frogs that showed an implication of asymmetrically enhanced neck reflexes after UL (Kolb, 1955) as after eccentrically mounting a weight on the head (Straka and Dieringer, 1995) for the postural recalibration.

Pharmacological alterations of the time course of the postural recovery after UL by systemic drug injections was used to elucidate a potential involvement of specific neurotransmitters and neuromodulators in the underlying central nervous plasticity (see Dieringer, 1995). Sedating and arousing drugs have been shown to delay and facilitate the normalization process, respectively
(Bienhold et al., 1981). A similar effect was observed with cholinergic drugs, which causes a postural decompensation (cholinomimetics) or reduction (cholinolytics) of the postural asymmetry (Bienhold and Flohr, 1980; Bienhold et al., 1981), compatible with the established role of cholinergic synapses in vestibular signal processing in frog (Rossi et al., 1980; Bernard et al., 1985; Kasik et al., 1986). A potential role of glutamate receptors for the postural recovery was studied in a series of experiments that tested the influence of systemically applied NMDA receptor blockers on the time course and magnitude of the lesion-induced head deviation (Flohr and Lüneburg, 1993). According to the results of the latter study, NMDA receptors are involved in the recovery, but not in the maintenance of the normal head position once it has been resumed. While these pharmaco-behavioral results have a relative importance for confining the post-lesional period of presumed neural plasticity, the systemic approach of 


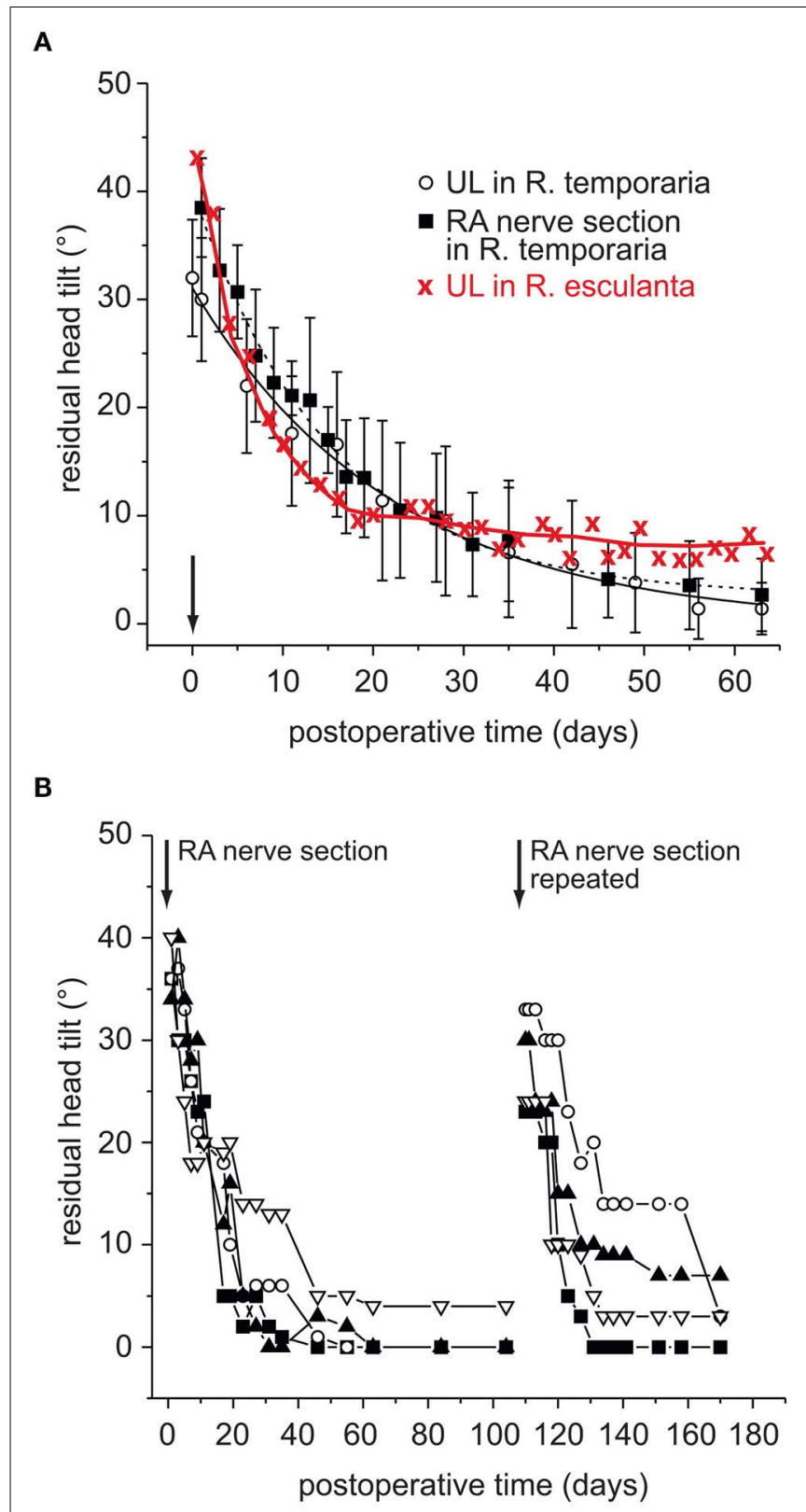

FIGURE 4 | Time course of recovery from the postural asymmetry after a unilateral vestibular lesion in adult frog. (A) Angle of the head roll tilt as a function of postoperative time in grass frog (Rana temporaria) after UL or selective section of the anterior VIIIth nerve branch (RA) and in water frog (Rana esculenta) after UL; data on UL in Rana esculenta adopted from Kolb (1955) and in Rana temporaria from Flohr et al. (1981). (B) Comparison of the residual head tilt angles in four specimen of Rana temporaria in which the same RA nerve branch was re-sectioned 100 days after the first lesion; modified and adopted from Goto et al. (2002).

drug application in combination with the commonality and widespread occurrence of the tested transmitter systems in the CNS prevents further specification of the site of action. Despite these known limitations in the interpretation, central vestibular nuclei were commonly assumed as the predominant site of the neural plasticity processes.
PERIPHERAL AND CENTRAL VESTIBULAR PLASTICITY AFTER UNILATERAL VESTIBULAR LOSS

A partial or complete unilateral loss of vestibular sensory inputs triggers a number of morpho-physiological changes that usually have been associated with different aspects of the behavioral recovery (Dutia, 2010). The reliable improvement of acute postural deficits over time is generally interpreted as the consequence of neural changes that cause spatio-temporal accurate compensation or substitution of the impaired vestibular sensation (Flohr et al., 1985). However, a number of experiments in frogs have shown that even though some of the observed neural changes are in favor of a recalibration of central vestibular activity, other cellular and network modifications cause deterioration of the spatial response vectors of individual neuronal populations and thereby potentially alter the behavioral output and induce inappropriate motor reactions (Goto et al., 2000, 2001; Rohregger and Dieringer, 2003). Furthermore, the time course of plastic changes in central vestibular signal processing differs from that of the postural recovery (Straka et al., 1993), thereby challenging the vestibulo-centric view of the "compensation" process.

In the following, different plasticity processes at the cellular and circuit level in the brainstem and spinal cord in frog after a unilateral vestibular loss will be described. Potential relations with the behavioral recovery of lesion-induced deficits and possible consequences for the precision of vestibulo-motor responses will be discussed. Major post-lesional changes in general include modifications of intrinsic membrane properties, specifically augmented synaptic efficacy of available intact inputs, generation of new or extension of existing morphological connections within the vestibulo-motor circuitry, alterations in convergence patterns of intact vestibular signals and sensory substitution (e.g., Straka et al., 2005; Dutia, 2010). A number of these conceptually different plasticity processes were initially discovered in frogs (see Dieringer, 1995, 2003) and later confirmed in different vertebrate species, whereas others appear to be part of a more amphibianspecific plasticity regime that includes regeneration of vestibular nerve afferents under certain experimental conditions. In contrast, changes in intrinsic membrane properties of vestibular neurons after a loss of one labyrinth as shown in guinea pig (Beraneck et al., 2003, 2004) have so far not been reported in frog. However, this is not due to a general absence of such a plasticity phenomenon in frog, but rather due to the lack of respective studies that compare known intrinsic neuronal properties of frog tonic and phasic $2^{\circ} \mathrm{VN}$ (Straka et al., 2004; Beraneck et al., 2007) before and after the lesion. Assuming the presence of basic reaction mechanisms that only differ in magnitude between different species, a general hypothesis is derived from the results obtained in guinea pigs after UL (Beraneck et al., 2003, 2004). Accordingly, on the ipsilesional side in frog, the overall tonic response properties might increase, mainly by a process, whereby phasic $2^{\circ} \mathrm{VN}$ express a more sustained discharge during current step-evoked depolarization. In addition, oppositely oriented changes are predicted for $2^{\circ} \mathrm{VN}$ on the contralesional side. A potential mechanism that allows phasic neurons to become more tonic is a reduction in the density of dendrotoxinsensitive potassium channels (Beraneck et al., 2007), similar to the situation of chicken tangential vestibular nucleus neurons during late embryogenesis (Gamkrelidze et al., 1998, 2000). Thus, 
future studies in the frog model will reveal a potential homeostatic plasticity of electrophysiological properties that include mirror image-like alterations of ion channel conductances and their functional consequences in the bilateral vestibular nuclei after UL as described for the synaptic charge transfer in the chicken tangential vestibular nucleus (Shao et al., 2012).

\section{REGENERATION OF VESTIBULAR NERVE AFFERENTS AFTER VIIITH NERVE SECTION}

A particular reaction after transection of the VIIIth nerve without removal of labyrinthine endorgans is a regeneration of afferent fibers and a reinnervation of the remaining epithelium in the sensory periphery. This plasticity phenomenon is common in amphibians (Sperry, 1945; Hernandez et al., 1998; Goto et al., 2002) and birds (Haque et al., 2008) but apparently absent in mammals. In frog, regeneration of vestibular afferents and reinnervation occurs both within the sensory epithelium after a nerve section distal to Scarpa's ganglion (Figure 4B; Hernandez et al., 1998) as well as centrally in the vestibular nuclei after a nerve section between the ganglion and the brainstem (Newman and Honrubia, 1992). Independent of the site of nerve section, peripheral and central regenerating afferent fibers form appropriate projections and reinnervate adequate vestibular endorgans and central neurons in the vestibular nuclei, respectively (Newman et al., 1986, 1987; Hernandez et al., 1998). The remarkable spatio-temporal precision of this process is best illustrated by the reappearance of head motion-driven activity in afferent fibers and vestibulo-motor responses with gains that are comparable to those of controls (Hernandez et al., 1998; Goto et al., 2002). With the exception of particular organizational differences in afferent fiber diameters and reinnervation patterns of hair cells in different areas of the sensory epithelium by thin and thick fibers, this plasticity mechanism is specific and results in a complete functional recovery of vestibular function if the sensory periphery remains preserved after the lesion. In fact, the persisting intact receptor epithelium exerts a presynaptic influence on the physiological characteristics of regenerating and reconnecting axons, thereby ensuring a certain spatio-temporal precision (Hernandez et al., 1998). This mechanism, however, appears to be specific to non-mammalian species and thus has only limited implications for explaining "vestibular compensation" in mammals.

\section{CHANGES IN VESTIBULAR COMMISSURAL RESPONSES}

Brainstem commissural connections play an important role for the sensitivity of bilateral processing of head motion-related sensory signals (Shimazu, 1972; Graham and Dutia, 2001). Increased amplitudes of commissural responses in ipsilesional $2^{\circ} \mathrm{VN}$ of chronic frogs were among the first neural alterations observed after UL (Dieringer and Precht, 1977). Commissural field potentials, activated by electrical pulse stimulation of the contralateral VIIIth nerve in frog, typically consist of a disynaptic negative field potential (Figure 5A) that mirrors intracellularly recorded commissural EPSPs in $2^{\circ} \mathrm{VN}$ (Figure 5C; Ozawa et al., 1974). Compared to controls, commissural (Figures 5A,B) but not afferent field potentials (Figures 3E,F) are significantly enhanced $(\sim 100 \%)$ 2 month after UL, whereas regional distributions and depth profiles remain unaltered. This finding was interpreted as a general increase in synaptic efficacy of commissural excitatory inputs from the contralateral, intact side to ipsilesional $2^{\circ} \mathrm{VN}$ (Dieringer and Precht, 1977, 1979a,b; Kunkel and Dieringer, 1994), independent of degeneration (postganglionic lesion) or survival (preganglionic lesion) of the VIIIth nerve (Kunkel and Dieringer, 1994). Further specification of this plastic change in synaptic responsiveness by intracellular recordings of ipsilesional $2^{\circ} \mathrm{VN}$ in chronic UL frogs revealed increased amplitudes and faster rise times of commissural EPSPs (compare black and gray traces in Figure 5C), which, in contrast to controls, are able to trigger partial and full action potentials (Dieringer and Precht, 1977, 1979a). Functionally, this change is compatible with a reestablishment of the lesion-induced loss of resting activity in central vestibular neurons, potentially facilitating the recovery from behavioral deficits.

The survival of ipsilesional nerve afferents after a preganglionic UL allowed in chronic animals an electrical stimulation of these fibers with similar current thresholds as in controls (Kunkel and Dieringer, 1994). The absence of a general amplitude enhancement of VIIIth nerve afferent responses on the ipsilesional side precludes a global change in excitatory synaptic efficacy as the origin of the observed plasticity and suggests the implementation of more specific alterations in the synaptic transmission of commissural responses in $2^{\circ} \mathrm{VN}$ after lesion (Kunkel and Dieringer, 1994). Since excitatory commissural responses in frog $2^{\circ} \mathrm{VN}$ are transmitted by glutamate that activates both AMPA and NMDA receptors (Cochran et al., 1987; Knöpfel and Dieringer, 1988), both receptor subtypes could theoretically contribute to the observed increase in EPSP amplitude. However, NMDA components of commissural EPSPs in chronic frogs are not increased compared to controls (see dashed black and gray traces in Figure 5C; Knöpfel and Dieringer, 1988) and circumstantial evidence (Cochran et al., 1987) argues against an increased number or sensitivity of AMPA receptors as the cause for the facilitated commissural signals (for details see Dieringer, 1995). Moreover, the role of glutamate in transmitting both afferent and commissural signals onto $2^{\circ} \mathrm{VN}$ along with the restricted augmentation of the latter responses in ipsilesional $2^{\circ} \mathrm{VN}$, was used as an argument to preclude a general supersensitivity of glutamate receptors as the origin of the plasticity in excitatory commissural responses.

Accordingly, pre- and/or postsynaptic alterations of the synaptic transmission process as possible cause for the observed increased commissural excitation in ipsilesional $2^{\circ} \mathrm{VN}$ of chronic frogs were considered unlikely. This led to the suggestion of reactive synaptogenesis of excitatory commissural connections as an alternative mechanism to explain, at least in part, the observed changes. In particular, a morphological expansion of commissural synapses onto more proximal dendrites, in addition to those present on distal dendrites as in controls, was hypothesized as a cause for the altered amplitude and rise time of the commissural excitation (Dieringer and Precht, 1979a). Even though, direct morphological evidence for this interpretation is missing (see Dieringer, 1995), more recent studies (Goto et al., 2000, 2001) using a specific vestibular nerve lesion paradigm appears to concur with this idea (see below). Nonetheless, the still unsatisfying interpretation of the augmented commissural excitation in chronic frogs after UL without a clearly confirmed underlying mechanism prevails until today. 
A

Commissural field potentials in vest. nuc.

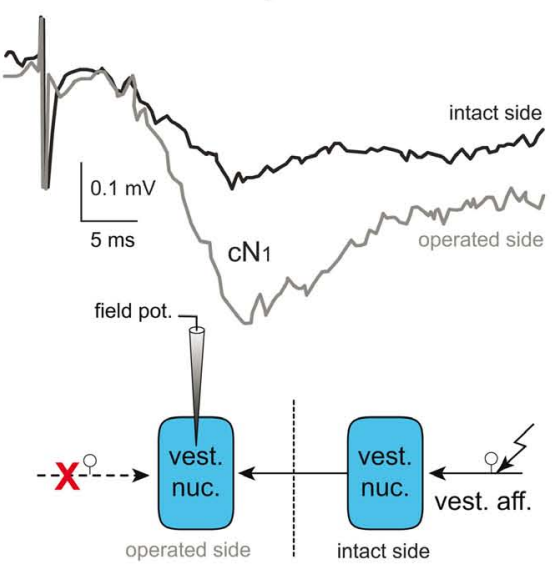

B

\section{Commissural field potentials in VN}

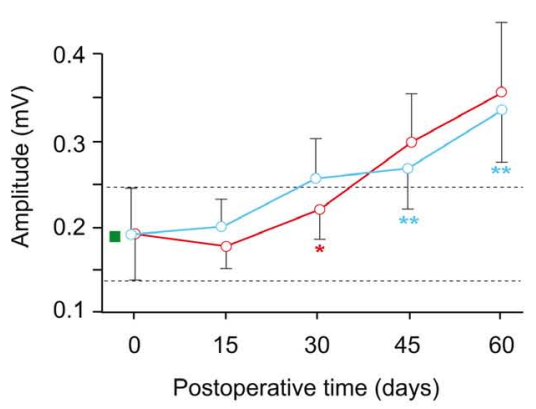

- control

preG - operated side

o postG - operated side

C

control

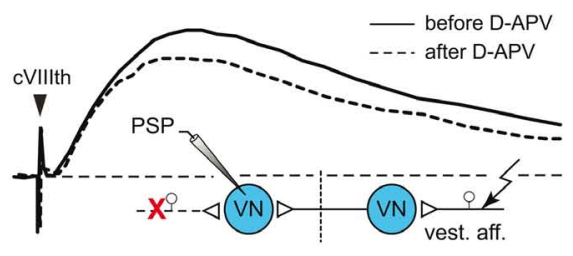

D

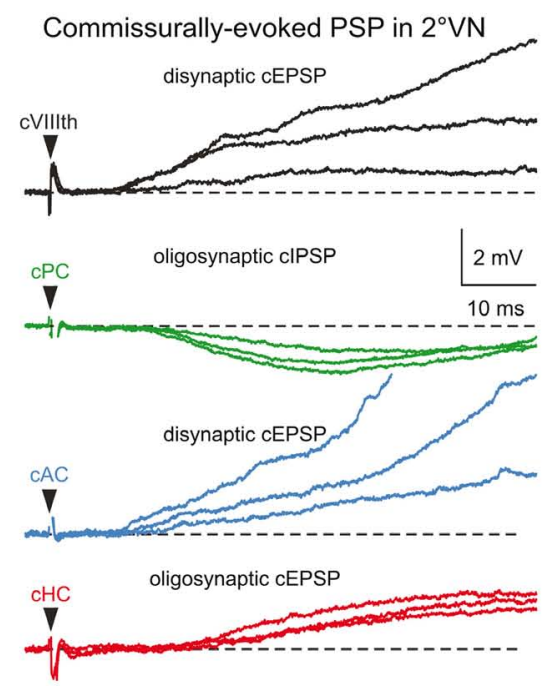

FIGURE 5 | Cellular origins of lesion-induced plastic changes in vestibular commissural pathways in frog. $(\mathbf{A}, \mathbf{B})$ Pre- $\left(\mathrm{CN}_{0}\right)$ and postsynaptic components $\left(\mathrm{CN}_{1}\right)$ of vestibular commissural field potentials $(\mathbf{A})$ recorded in the vestibular nuclei on the intact and operated side of chronic UL frogs following electrical stimulation of the contralateral VIIIth nerve (scheme); changes in vestibular commissural field potential amplitudes after a pre(preG) and postganglionic (postG) UL (B); modified and adapted from Straka et al. (1993) and Kunkel and Dieringer (1994). (C) Vestibular commissural EPSPs in 2 VN of controls (left) and on the operated side of chronic UL frogs (right) activated by electrical stimulation of the intact VIIIth nerve (scheme); bath application of D-APV $(25 \mu \mathrm{M})$ in vitro unmasks similar contributions of NMDA receptor-mediated components in responses of $2 \mathrm{VN}$ in controls and
E
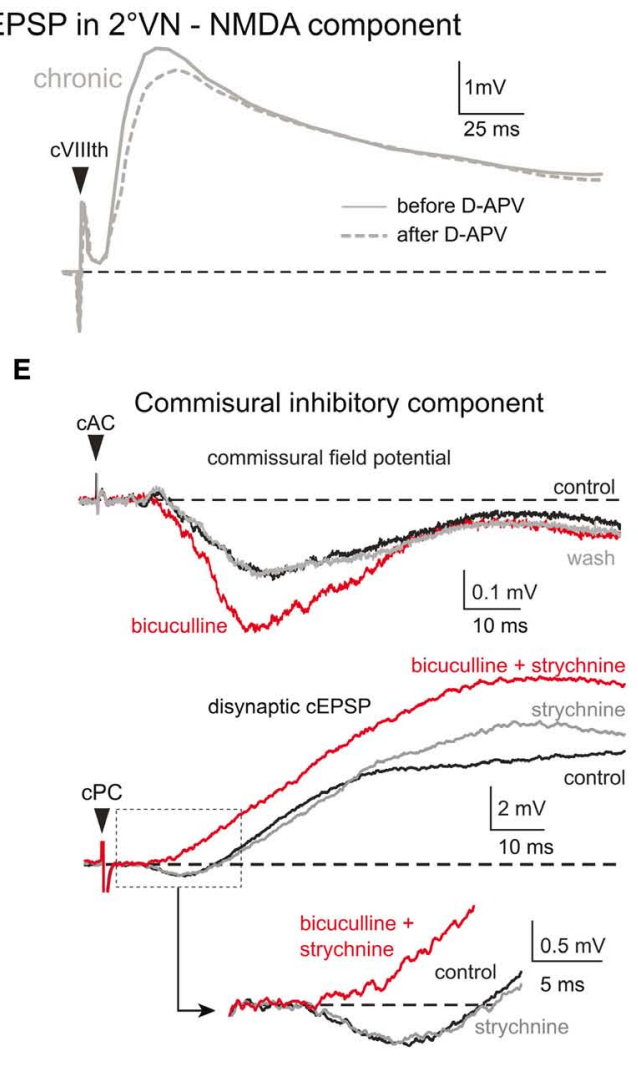

on the operated side of chronic UL frogs; modified and adapted from Knöpfel and Dieringer (1988). (D) Commissural vestibular responses recorded in vitro in an identified $2^{\circ}$ anterior vertical semicircular canal (AC) neuron following electrical stimulation of the entire contralateral VIIIth nerve (black trace) or individual branches to the contralateral posterior canal (PC, green trace), AC (blue trace), and horizontal canal (HC, red trace). (E) Sensitivity of contralateral semicircular canal (cAC, CPC) nerve-evoked vestibular commissural field potentials (upper traces) and commissural EPSPs in 2VN (lower traces) to in vitro bath-applied antagonists that block the GABAergic ( $5 \mu \mathrm{M}$ bicuculline) and glycinergic ( $2 \mu \mathrm{M}$ strychnine) transmission; note the increase in amplitude of extra- and intracellular recorded responses. (D,E) Modified and adapted from Malinvaud et al. (2010). 
Based on a recent functional reevaluation of frog vestibular commissural organization (Holler and Straka, 2001; Malinvaud et al., 2010), there is an alternative interpretation of the data by Dieringer and Precht (1977). The explanation for the increased excitatory vestibular commissural responses in chronic frogs after UL in the initial report as in all subsequent studies (see Dieringer, 1995) was based on the until then unquestioned finding that frogs, in contrast to cats, have an excitatory vestibular commissure. This was concluded from the presence of negative vestibular commissural field potentials and EPSPs in frog $2^{\circ} \mathrm{VN}$ (Ozawa et al., 1974) after stimulation of the entire contralateral VIIIth nerve (Figures 5A,C). More recent studies, however, that employed a specific electrical stimulation of individual labyrinthine nerve branches, revealed in individual semicircular canal-related $2^{\circ} \mathrm{VN} \mathrm{a}$ plane-specific commissural IPSP (green trace in Figure 5D) from the contralateral coplanar canal in frog (Holler and Straka, 2001; Malinvaud et al., 2010) as reported earlier in cat (Kasahara and Uchino, 1971). This canal-specific IPSP, however, is masked in frog by commissural EPSPs from most non-coplanar semicircular canal (blue and red traces in Figure 5D) and otolith organs, thereby causing a net slow rising excitation in $2^{\circ} \mathrm{VN}$ when stimulating the entire VIIIth nerve (black trace in Figure 5D), consolidating the latter results with the initial report of Ozawa et al. (1974).

Based on the recent, more elaborate functional organization of commissural connections in frog, the observed increase in amplitude and dynamics of the commissural excitation of $2^{\circ} \mathrm{VN}$ in chronic UL frogs after VIIIth nerve stimulation (e.g., Dieringer and Precht, 1977, 1979a,b; Knöpfel and Dieringer, 1988; Kunkel and Dieringer, 1994) might be caused by a reduction of semicircular canal-specific commissural IPSP rather than by an increase in commissural EPSP amplitudes. In fact, evidence for such an interpretation comes from in vitro experiments in brainstem preparations of intact frogs where the commissural inhibition was pharmacologically blocked by GABAergic and glycinergic antagonists (Figure 5E), causing an augmentation of the net commissural excitation (lower traces in Figure 5E; Malinvaud et al., 2010) as seen in the altered responses of $2^{\circ} \mathrm{VN}$ in chronic UL frogs. Moreover, a lesion-induced reduction of the commissural inhibition in ipsilesional semicircular canal-related $2^{\circ} \mathrm{VN}$ is also present in chronic frogs after section of the anterior branch of the VIIIth nerve (Goto et al., 2001). Thus, the latter studies and the new lines of arguments offer an alternative explanation for the plastic changes that were previously interpreted by an increase in vestibular commissural excitation. Accordingly, the increase of the commissural excitation is not caused by an augmentation of excitatory response components but rather by a decrease in the commissural inhibition to ipsilesional $2^{\circ} \mathrm{VN}$, in line with observations on cellular mechanisms that are involved in rebalancing the commissural system in mammalian species (Graham and Dutia, 2001; see Olabi et al., 2009; Dutia 2010).

The plastic changes in the commissural system in chronic UL frogs (Dieringer and Precht, 1977, 1979a) were initially interpreted as a mechanism that is directly involved in the postural recovery by assisting the reestablishment of a bilateral symmetric spontaneous activity in central vestibular neurons. In fact, the significant increase of the commissural excitation 2 month after the lesion was assumed to be the cause for the normalized posture in these animals, partly because this increase saturated at the same time (Kunkel and Dieringer, 1994). However, experiments that determined onset and time course of the post-lesional commissural changes indicated that a first significant increase in commissural field potential amplitudes occurs only $\sim 30$ days after UL and progresses slowly thereafter (Figure 5B). This, however, is too late and thus at variance with the considerably faster time course of the postural recovery (Figure 4A) that proceeds asymptotically with a $50 \%$ recovery of the initial postural asymmetry after $\sim 15$ days (Kunkel and Dieringer, 1994).

The delayed onset of plastic changes in commissural signaling and its presumed influence on the resting activity of central vestibular neurons is in agreement with the time course of alterations in the metabolic activity in the vestibular nuclei after UL (Flohr et al., 1981, 1989). Similar to the time course of the increase in commissural responses, the recovery of the markedly reduced deoxyglucose uptake in central vestibular neurons immediately after the lesion is delayed by $\sim 30$ days. Thus, the obvious discrepancy in the timing of changes in commissural signaling, metabolic activity in the vestibular nuclei, and effective body posture (Figures 4A and 5B; Straka et al., 1993) suggests that plasticity processes other than those in the vestibular commissural system or the vestibular nuclei might be at the origin of the postural normalization. This assumption also concurs with the view on neural plasticity after UL as a distributed process that also includes areas outside the vestibular nuclei (Llinás and Walton, 1979).

\section{SYNAPTIC REORGANIZATION}

Reactive synaptogenesis at multiple hierarchical levels of the CNS is a common morpho-physiological mechanism that has been shown to cause reorganization of sensory signal processing after peripheral or central lesions in vertebrates (Kaas, 2000). With respect to an experimentally induced peripheral loss of vestibular inputs, only few studies have so far explored the interaction between synaptic inputs from sectioned, silenced and remaining, intact labyrinthine nerve afferents or central inputs to $2^{\circ} \mathrm{VN}$ (Dieringer, 2003). The resulting competition between intact and sectioned fibers for synaptic access to $2^{\circ} \mathrm{VN}$ after a partial vestibular nerve section is at variance with the situation after a complete UL where all fibers are silenced. While the induced reaction mechanisms for the overall population of ipsilesional afferent fibers consequently differ between the two experimental manipulations, other simultaneously and/or sequentially occurring plasticity processes might only vary in magnitude. Thus, a partial vestibular nerve section is by definition not just a smaller version of a complete UL but induces an interesting and unique condition with respect to potential afferent synaptic plasticity that might be relevant for the postural recovery after the lesion.

While a complete UL generates a relatively defined experimental condition by silencing all vestibular nerve afferent fibers on one side, a partial removal of vestibular inputs and its provoked functional plasticity is relevant for understanding those events that are triggered by various types of incomplete impairment of vestibular sensation in human patients. Accordingly, the partial vestibular lesion model in frog offers an excellent possibility to gain insight into the synaptic plasticity after a specific, restricted disfacilitation of identified central neurons. A selective section of 
the entire anterior branch of the VIIIth nerve or of single branches to individual endorgans creates a conflict situation between the remaining intact and the disfacilitated vestibular nerve afferent fibers with respect to the access to $2^{\circ} \mathrm{VN}$ (Goto et al., 2000, 2001, 2003). The section of the anterior VIIIth nerve branch eliminates sensory inputs from the utricle, the saccule, the anterior vertical and the horizontal semicircular canal, while the posterior VIIIth nerve branch that mediates sensory inputs from the posterior canal and the lagena (the vertical otolith organ in frog) remains intact. The preganglionic nature of this nerve section ensures survival of the central projection of the sectioned anterior VIIIth nerve branch and thus offers the possibility for electrical activation of the silenced nerve fibers 2 months later, at a time when the postural asymmetry, as relevant marker for immediate static post-lesional deficits, has been normalized. Moreover, the possibility to activate monosynaptic EPSPs in ipsilesional $2^{\circ} \mathrm{VN}$ from the severed nerve stump facilitates the identification of those neurons that had been deprived of sensory inputs.

Chronic frogs that had received a section of the anterior VIIIth nerve branch expressed considerable alterations in the synaptic organization of afferent inputs from fibers in the remaining intact posterior VIIIth nerve branch on the operated side as well as of commissural inputs from the contralateral labyrinth (Figures 6A-C; Goto et al., 2000, 2001). On the ipsilesional side, field potentials evoked by stimulation of the intact posterior vertical semicircular canal nerve were enlarged throughout the vestibular nuclei (Figures 6A,B), and the total number of $2^{\circ} \mathrm{VN}$ with a monosynaptic input from this semicircular canal was significantly increased compared to controls (Figure 6D; Goto et al., 2000), suggesting an expansion of the latter afferent inputs onto those $2^{\circ} \mathrm{VN}$ that had been deprived of afferent vestibular inputs from the sectioned anterior VIIIth nerve branch. However, this synaptic
A

Afferent field potential in vest. nuc.

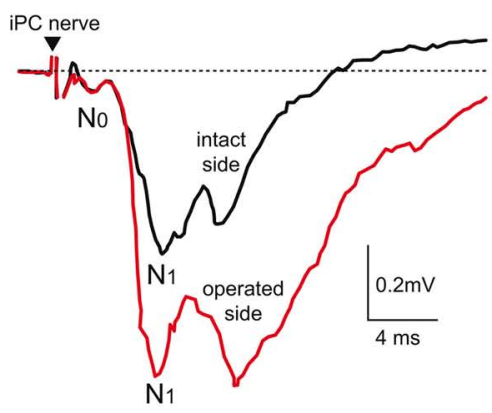

D

Monosynaptic EPSPs in $2^{\circ} \mathrm{VN}$
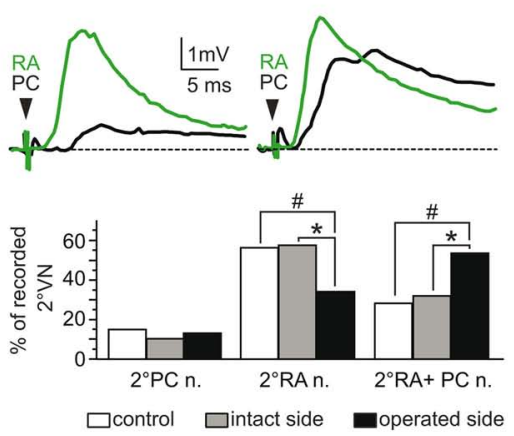

B

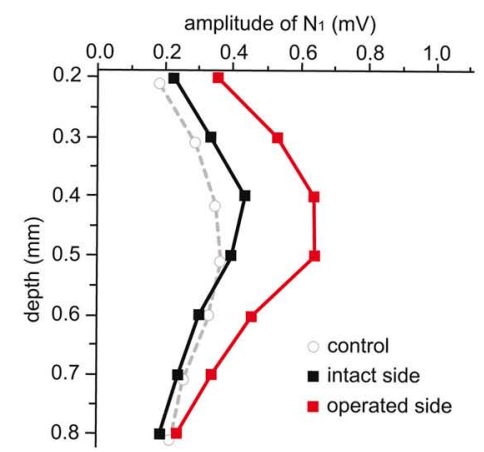

E

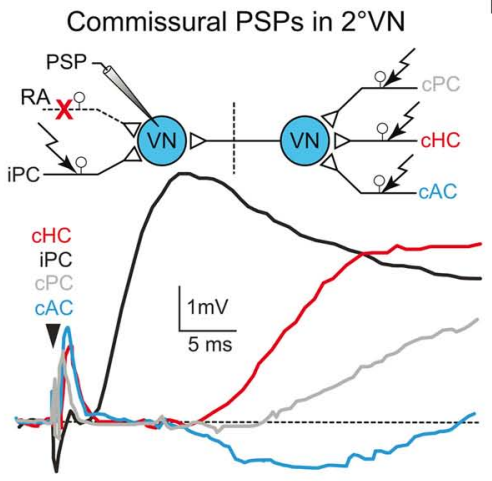

C

Commissural field potential in vest. nuc.
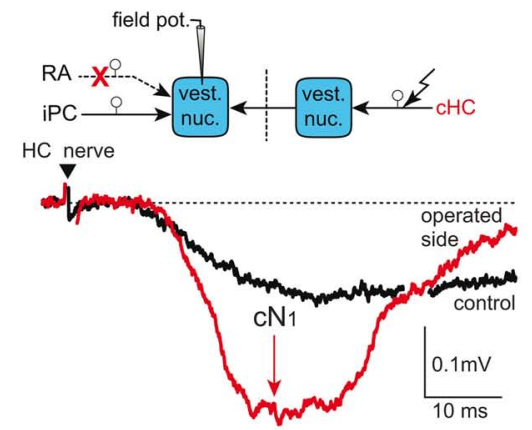

$\mathbf{F}$

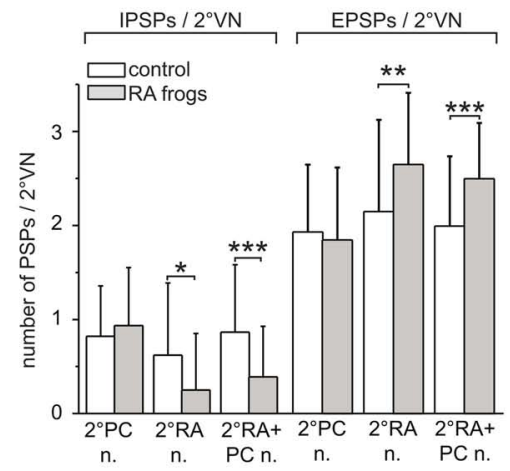

FIGURE 6 | Synaptic reorganization of intact vestibular inputs after labyrinthine nerve lesions. $(\mathbf{A}, \mathbf{B})$ Posterior semicircular canal (PC) nerve-evoked afferent pre- $\left(N_{0}\right)$ and postsynaptic $\left(N_{1}\right)$ field potential components (A) recorded on the intact and operated side of chronic frogs with a section of the anterior branch (RA) of the VIIIth nerve; the enhanced field potentials on the operated side extend throughout the entire nucleus as indicated by the amplitude depth profile (B). (C) Contralateral horizontal semicircular canal $(\mathrm{HC})$ nerve-evoked postsynaptic commissural field potentials (cN1) recorded in a control frog and on the operated side of a chronic RA frog; the sites of lesion, electrical stimulation and recording are illustrated in the scheme. (D) Convergence pattern of monosynaptic afferent responses in two $2 \mathrm{VN}$ after separate stimulation of the PC nerve (black traces) and the RA of the VIIIth nerve (green traces); after RA nerve section, the percentages of $2^{\circ} \mathrm{RA}$ neurons and of $2^{\circ} \mathrm{RA}+\mathrm{PC}$ but not of $2^{\circ} \mathrm{PC}$ neurons on the operated side of chronic RA frogs are complementarily altered, with respect to the pattern on the intact side ( ${ }^{*} P \leq 0.01$ ) or controls ( $\left.P \leq 0.0001\right)$; data adopted from Goto et al. (2000). $(\mathbf{E}, \mathbf{F})$ Plasticity of commissural semicircular canal inputs in $2^{\circ} \mathrm{VN}$ of chronic RA frogs; typical afferent and commissural responses of a $2^{\circ} \mathrm{PC}$ neuron (E); the pattern consists of an afferent (i) PC nerve-evoked monosynaptic EPSP and commissural (c) anterior vertical canal (AC) nerve-evoked IPSP, CHC, and CPC nerve-evoked EPSPs; ipsi- and contralateral stimulation and recording sites are illustrated (scheme); the relative proportions of IPSPS/2VN and EPSPs/2VN (F) in chronic RA frogs (gray bars) are significantly altered $\left({ }^{*} P \leq 0.01,{ }^{*} P \leq 0.001,{ }^{*} *{ }^{*} P \leq 0.0001\right)$ in a complementary fashion on the operated side in $2^{\circ} \mathrm{RA}$ and $2^{\circ} \mathrm{RA}+\mathrm{PC}$ but not in $2^{\circ} \mathrm{PC}$ neurons compared to controls (white bars); data adopted from Goto et al. (2001). 
reorganization is not restricted to the remaining intact afferent vestibular nerve inputs from the same side, but also extends to commissural inputs from the contralateral semicircular canal nerves (Figures 6C,E,F; Goto et al., 2001).

After separate stimulation of the three contralateral, intact semicircular canal nerve branches, inhibitory commissural inputs were reduced in number and amplitude, whereas the relative occurrence and magnitude of excitatory commissural responses were augmented in those $2^{\circ} \mathrm{VN}$ that were disfacilitated by the peripheral nerve lesion (Figures 6E,F). Thus, the inactivated monosynaptic inputs from the sectioned afferent fibers in the anterior VIIIth nerve branch are functionally substituted by an expansion of inputs from afferents of the remaining intact homolateral posterior vertical canal and by cooperative changes in semicircular canal-related commissural inputs from the contralateral side. These modifications are specific, since afferent and commissural responses of posterior vertical canal $2^{\circ} \mathrm{VN}$ on the same side, which were not disfacilitated by the lesion, remain unaltered (Figures 6D,F; Goto et al., 2000, 2001).

The new excitatory response components from vestibular nerve afferents to the disfacilitated $2^{\circ} \mathrm{VN}$ might either represent new connections, formed by axonal sprouting from the remaining intact posterior VIIIth nerve branch (afferents from the posterior vertical canal and/or the lagena), or reactivated silent synapses that already existed before the lesion. In addition, new excitatory inputs to the disfacilitated $2^{\circ} \mathrm{VN}$ are not limited to intact afferent or commissural vestibular inputs but include excitatory synaptic inputs from ascending propriospinal afferent projections as evidenced by the increased axonal arborization of this pathway in the ipsilesional vestibular nuclei in chronic UL frogs (Dieringer et al., 1984).

Based on these results, a set of general rules can be extracted by including data obtained after a selective section of either utricular afferent fibers or after a combined section of the horizontal and anterior vertical canal nerve branch (Goto et al., 2002). Accordingly, the synaptic reorganization is activity-dependent, since the expansion of excitatory signals is restricted to intact inputs from vestibular nerve branches, commissural fibers or ascending spinal projections. The retention of labyrinthine afferent synapses onto $2^{\circ} \mathrm{VN}$ after the preganglionic nerve section precludes a competitive interaction between active (intact) and inactive (axotomized) axon terminals. Rather, the presence of spontaneous or modulated activity of intact neurons is the likely trigger for an expansion of their synaptic inputs onto disfacilitated $2^{\circ} \mathrm{VN}$, compatible with the complete reversibility of the latter plasticity after regeneration of the sectioned peripheral axons and reinnervation of the previous sensory epithelium (Figure 4B; Goto et al., 2002). The synaptic reorganization is gradual, and its extent appears to depend on the amount of sensory fibers that were silenced by the lesion (Goto et al., 2002). Thus, a utricular ( 4000 fibers) but not semicircular canal nerve $(\sim 1500$ fibers $)$ section provokes a significant expansion of intact excitatory inputs onto those $2^{\circ} \mathrm{VN}$ that were disfacilitated by the lesion.

As after UL, the onset of synaptic changes in the vestibular nuclei, triggered by the partial VIIIth nerve lesion is delayed compared to the onset of the postural recovery from those lesions (Goto et al., 2002). This precludes changes in the synaptic arrangement of central vestibular neurons as a major contributor to the reestablishment of a normal posture after a partial or complete loss of one labyrinth. The apparent substitution of the reduced synaptic excitation of $2^{\circ} \mathrm{VN}$ by intact excitatory inputs is analogous to the situation of denervated muscle fibers that accept a heteronymous innervation to avoid degeneration (Kaas, 2000). Therefore, cooperative changes that include expansion of excitatory and contraction of inhibitory inputs to disfacilitated neurons appear to represent a general, ubiquitous mechanism. The synaptic reorganization of vestibular circuitry in frog at a period when the initial asymmetric posture is normalized again, does not exclude that other mechanisms, such as changes of intrinsic cellular properties, might contribute to the postural recovery at earlier post-lesional periods.

Reactive synaptogenesis, even though it appears to be advantageous for the survival of deafferented neurons, has an important functional consequence. The newly acquired excitatory synaptic inputs to $2^{\circ} \mathrm{VN}$ originate from vestibular endorgans that convey inappropriate signals onto disfacilitated neurons and thereby impair the spatio-temporal specificity of the sensory-motor transformation. Thus, the cooperative changes in synaptic inputs might be beneficial for the survival of deprived $2^{\circ} \mathrm{VN}$ and likely assist in the reduction of the asymmetry between the resting discharge of bilateral $2^{\circ} \mathrm{VN}$, however, the rescue of the latter neurons is at the expense of the precision in the tuning of vestibular reflexes. Such a deterioration of spatio-temporal parameters of the signal processing in "compensated" animals after a peripheral nerve lesion also complies with the notion that neural plasticity is not primarily oriented toward a functionally appropriate reestablishment of impaired vestibulo-motor responses.

\section{INADEQUATE VESTIBULAR REFLEXES AFTER SYNAPTIC REORGANIZATION}

The apparent absence of a targeted neural plasticity process that compensates functional deficits was evidenced by the results of a series of experiments that used specific vestibular nerve lesions in frog (Rohregger and Dieringer, 2003). The pronounced synaptic reorganization of vestibular nerve afferent, commissural and ascending spinal inputs at the level of $2^{\circ} \mathrm{VN}$ after UL as after partial VIIIth nerve lesions suggests that the spatial and dynamic precision of the disfacilitated $2^{\circ} \mathrm{VN}$ is considerably altered by this process. In particular, the acquisition of new excitatory inputs from vestibular endorgans other than the original organ during the post-lesional plasticity (Figures 7A,B) is not necessarily functionally meaningful and adaptive and in fact appears to be even detrimental (Goto et al., 2000, 2001; Rohregger and Dieringer, 2003). The newly acquired inputs after a selective section of the anterior VIIIth nerve branch differ from the original afferent inputs in their response vectors, and thus convey spatio-temporally inappropriate signals to the disfacilitated neurons (Figure 7B). Assuming that the projections to efferent recipients of $2^{\circ} \mathrm{VN}$ with new inputs remain unchanged, functionally inadequate signals are relayed to the default motor targets and thus cause erroneous behavioral responses. This is in fact the case as evidenced by the appearance of inappropriate posterior vertical semicircular canal responses in contralesional frog abducens motoneurons after a lesion of the anterior VIIIth nerve branch (Goto et al., 2000). Thus, as a result, the spatial response vector of contra- but not ipsilesional 


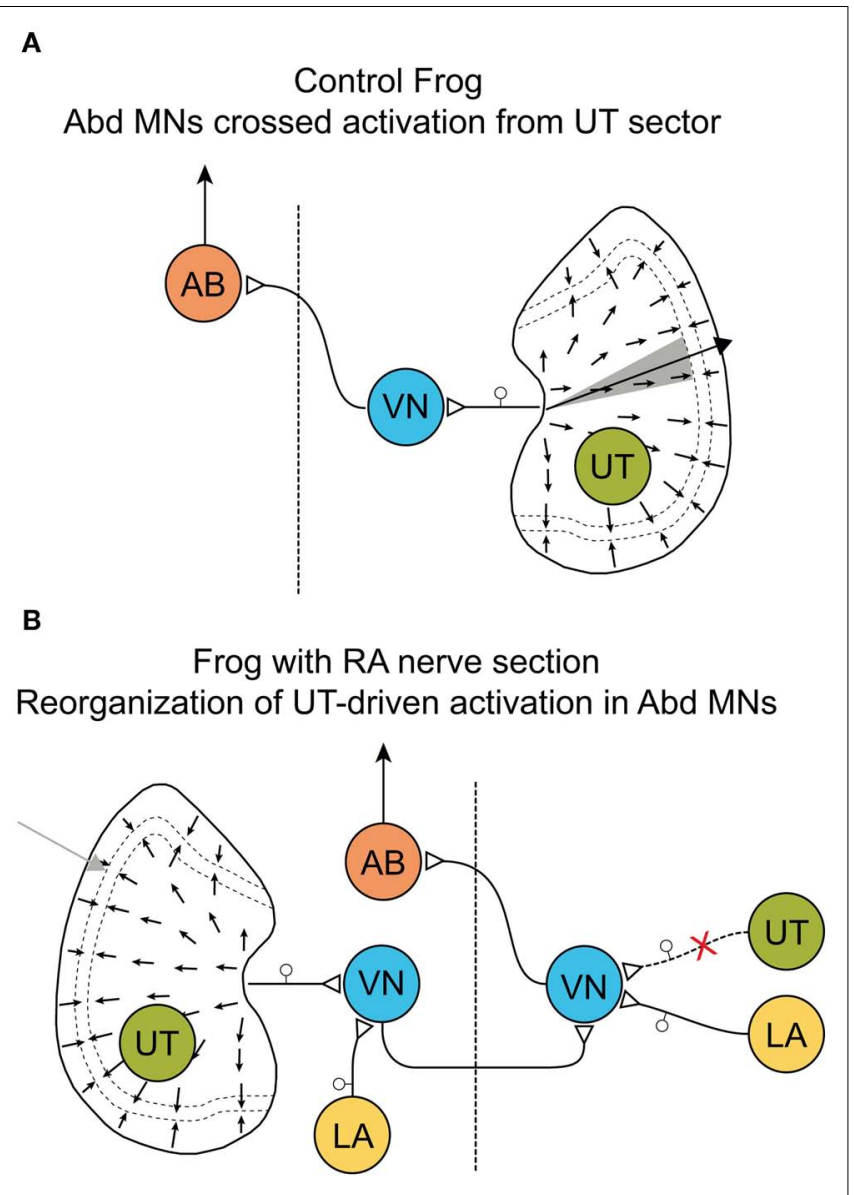

FIGURE 7 | Modification of response vectors in abducens motoneurons after labyrinthine nerve lesions. (A,B) Schematic diagram of signaling pathways before (A) and after section (B) of the anterior branch (RA) of the VIIlth nerve; afferent vestibular nerve signals during linear acceleration in contralateral (left) abducens motoneurons (AB) of controls (A) originate from a sector of hair cells (gray) on the right utricle (UT) and are mediated by neurons in the vestibular nucleus (VN) that excite contralateral $A B$. In chronic RA frogs (B) with a nerve section on the right side, the vestibular responses in the left $A B$ recovered but now originate during linear acceleration from hair cells located laterally with respect to striola on the left, ipsilateral UT; after convergence with spatially inappropriate signals from the lagena (LA, yellow) in the ipsilesional VN, these signals access contralateral $A B$ through the default excitatory crossed projection; scheme modified and adapted from Rohregger and Dieringer (2003).

abducens motoneurons to linear and angular head acceleration is modified, which leads to a deterioration of the spatial tuning of vestibulo-motor responses (Rohregger and Dieringer, 2003).

The change in vector orientation of these responses, however, is highly variable between different specimen, most likely due to individual degrees of reorganization of signals from the remaining intact posterior vertical canal and the lagena (Figure 7B). Again, the deterioration in spatial precision of the VOR is at variance with the idea of targeted plasticity processes that aim toward a functional compensation of lesion-induced behavioral deficits. More likely, cellular response cascades are triggered in the disfacilitated neurons that ensure a general survival of these neurons by preventing the induction of apoptotic cellular consequences. The changes in both synaptic circuitry and cellular properties of $2^{\circ} \mathrm{VN}$ might thus be the expression of a fundamental neural reaction pattern that is common between sensory modalities and vertebrate species.

\section{FUNCTIONAL ROLE OF PROPRIOSPINAL PLASTICITY FOR THE POSTURAL RECOVERY AFTER UL}

The obvious discrepancy between onset and timing of the neural changes in the vestibular nuclei (Figure 5B) and the recovery from the postural asymmetry after UL (Figure 4A) precludes a causal relationship between the former and the latter plasticity process (Straka et al., 1993). In addition, the vestibular nuclei are by no means the only place at which the neural organization becomes altered in response to a peripheral labyrinthine lesion. As a consequence, "vestibular compensation" is likely not accomplished by a single, local process nor does it entirely rely on vestibular signals from remaining intact vestibular endorgans. Rather, the functional normalization after the loss of vestibular sensory inputs represents the integrated result of a multitude of distributed neural modifications that occur at different time intervals after the lesion as suggested earlier (Llinás and Walton, 1979; Dieringer, 1995). The observation of increased densities of synaptic terminations of ascending propriospinal fibers within the ipsilesional vestibular nuclei after UL (Dieringer et al., 1984) suggests that proprioceptive signals play an important role in the recovery process from the lesion-induced deficits. In terrestrial tetrapods, these sensory inputs are excellently suited for providing an appropriate reference frame that supplies information on the position of the "body in space" after a unilateral loss of labyrinthine function. However, the dynamics and spatial precision for detecting and encoding relative positions of head-body-limbs with respect to the ground is relatively low and therefore limited to substituting static vestibular reflexes such as tonic head/body deviations. Thus, altered synaptic efficacy of the bilateral propriospinal circuitry might be the principal cause for the observed postural recovery.

Isolated brainstem-spinal cord preparations of frogs that had recovered from the postural asymmetry after UL exhibit an increased efficacy of monosynaptic uncrossed propriospinal responses within the ipsilesional brachial cord region (Figures 8A,B; Straka and Dieringer, 1995). Importantly, the amplitude of the uncrossed dorsal root-evoked ventral root potentials (DR-VRP) on the operated side began to significantly increase 7-15 days post-lesion, progressively augmented in parallel with the recovery of a normal static posture and reached a steady state after 30-40 days (Figures 8C,D). This increase in propriospinal response gain persisted after isolation of the spinal cord from the brainstem, and was therefore independent from changes at the central vestibular level (Straka and Dieringer, 1995).

Neural changes similar to those after UL were also seen 15 days after a selective unilateral section of the utricular nerve, but not after a respective section of branches to the horizontal semicircular canal or sacculus (Figure 8E). This suggests that the neural changes were initiated either specifically by bilaterally asymmetric utricular afferent inputs or by asymmetric proprioceptive inputs as a consequence of the utricular lesion-induced postural deficits (Tait and McNally, 1934). The two possibilities were explored in 


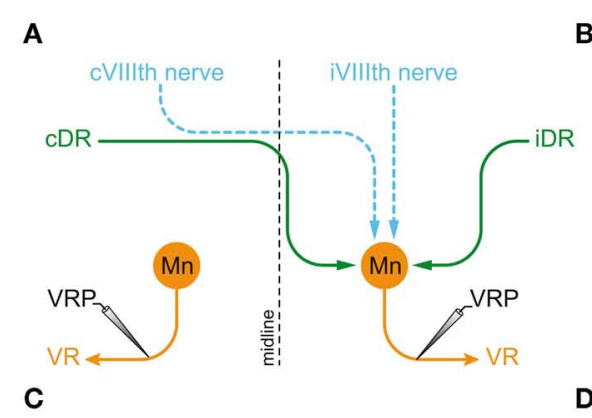

C

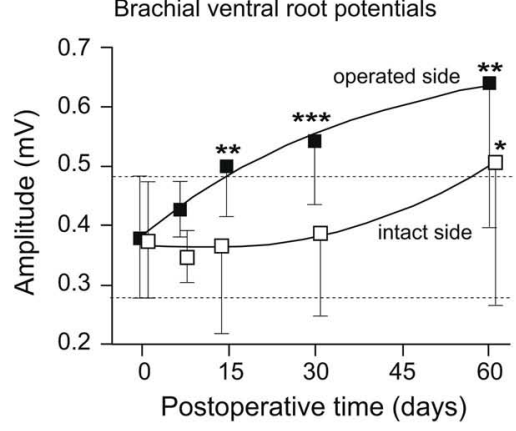

E

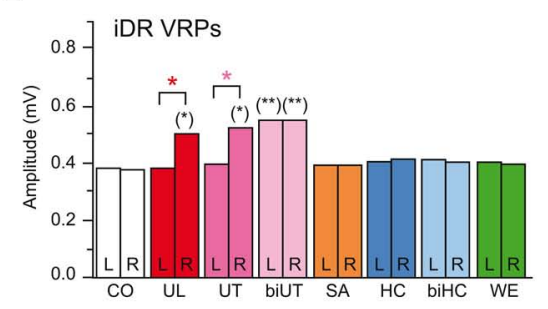

FIGURE 8 | Relation between propriospinal plasticity and postural recovery after labyrinthine nerve lesion. (A) Schematic drawing of bilateral vestibulo- (iVIIIth, cVIIIth nerve, dashed blue lines) and propriospinal (iDR, $c D R$, solid green lines) projections to motoneurons $(\mathrm{Mn})$ in the brachial spinal cord. (B) Ventral root (VR) potentials (VRP) recorded on the operated side after bilateral electrical stimulation of the $i D R, c D R$ are significantly increased in chronic UL frogs compared to those of controls. (C) Post-lesional time course of changes in mean amplitude of uncrossed iDR-VRP on the operated and intact side $\left({ }^{*} P \leq 0.05,{ }^{*} P \leq 0.001,{ }^{*} * P \leq 0.0001\right)$. (D) Comparison of the time course of plastic changes after UL in the amplitude of commissural vestibular field potentials (CFP, blue), uncrossed dorsal root-evoked ventral root potentials (VRP, red) on the operated side, respectively, and of the

$\mathbf{F}$

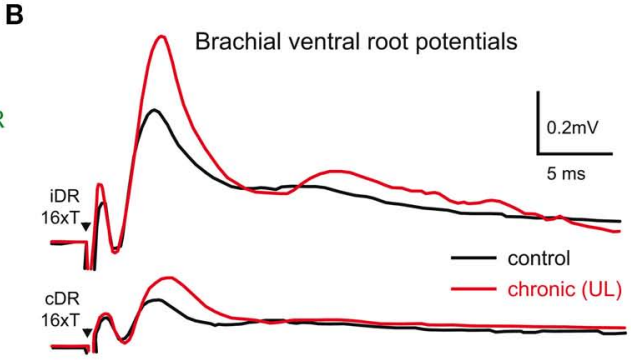

D
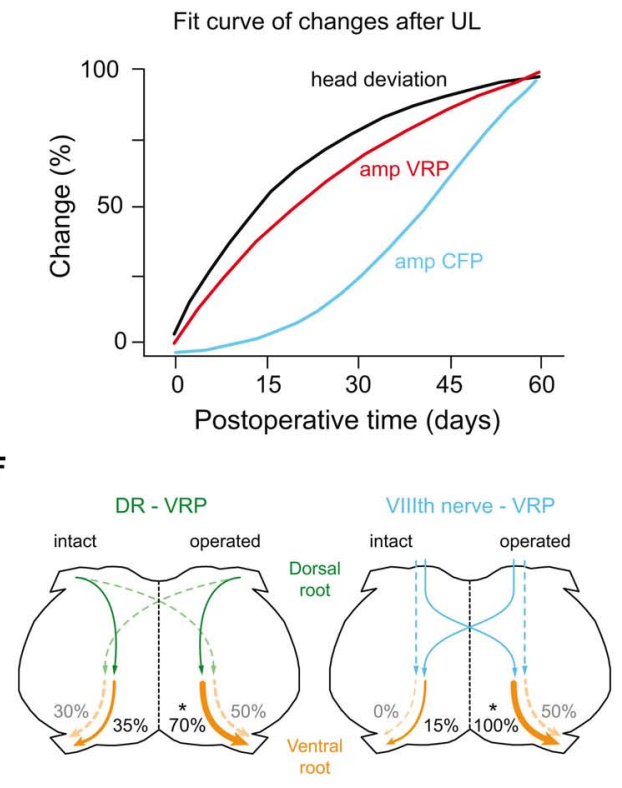

normalization of the head roll tilt (black). (E) Mean amplitudes of iDR-VRP on the left and right side in controls (CO) and in frogs 15 days after different selective labyrinthine nerve lesions or with a weight mounted eccentrically on the head (WE). UT, SA, HC, unilateral utricular, saccular, horizontal canal nerve section on the right side, respectively; biUT, biHC, bilateral utricular, horizonta canal nerve section; significance of difference between the left and right side is indicated by orange asterisks and with respect to controls by asterisks in parentheses $\left({ }^{*} P \leq 0.05\right.$; $\left.{ }^{*} P \leq 0.001\right)$. (F) Schematic drawing of a spinal cord cross-section summarizing relative changes in amplitudes with respect to controls ( ${ }^{*} P \leq 0.05$ ) in propriospinal (iDR/cDR-VRP; left) and vestibulo-spinal (iVIIIth/cVIIIth nerve-VRP; right) pathways after UL; data adopted from Straka et al. (1993) and Straka and Dieringer (1995). frogs with a bilateral utricular nerve section, which fails to provoke a postural asymmetry but disrupts the utriculo-vestibulo-spinal signal transmission on both sides. In these animals, the DR-VRP recorded on either side of the isolated brachial spinal cord is significantly enhanced (biUT in Figure 8E), demonstrating that the UL-induced spinal plasticity is directly related to the inactivation of utricular inputs and not a consequence of the lesion-induced postural deficits or asymmetric reafferent proprioceptive inputs (Straka and Dieringer, 1995).

The early changes in propriospinal efficacy after UL closely match the known time course of the postural recovery (red and black curve in Figure 8D; Straka et al., 1993), which proceeds exponentially in frogs and reaches about 50\% 2-3 weeks after the lesion. This is at variance with the considerably delayed onset of the changes in the efficacy of synaptic inputs in the ipsilesional vestibular nuclei (blue curve in Figure 8D). Thus, the normalization of the lesion-induced postural asymmetry appears to be an emergent property of adaptive processes that essentially include changes in propriospinal circuits (Figure 8F) following utricular afferent inactivation. The general validity of this finding has been confirmed by the presence of asymmetric neck reflexes in human patients following a unilateral vestibular loss (Brandt et al., 1997). Accordingly, a major contributor to the recovery of postural deficits after the loss of utricular function is the use of the reference frame that is implemented in the CNS of vertebrates by body-weight-supporting limb proprioceptive inputs. Thus as a prediction, tetrapods, which lack limb proprioceptive sensory signals, such as larval or adult frogs with an aquatic life style should 
be unable to recover from the asymmetric posture after the loss of one labyrinth.

\section{POST-LESIONAL PLASTICITY IN THE ABSENCE OF LIMB PROPRIOCEPTION}

The extension of the classical adult frog model for deciphering basic neural reaction patterns after an experimentally induced unilateral loss of vestibular function to premetamorphic larval stages offers the unique opportunity to further elucidate the potential role of limb proprioceptive signals in the plasticity that underlies "vestibular compensation." The delayed ontogenetic development of limbs in many amphibian larvae in combination with the buoyancy of the body in water restricts the potential use bodyweight-supporting proprioceptive signals. This situation allows studying post-lesional neural and behavioral consequences in a vertebrate model with a reduced functionality of the sensory system that appears to be significantly involved in the recovery from the lesion-induced postural deficits. The dominant role of limb proprioception and the increased synaptic efficacy of propriospinal circuits as the cause for the postural normalization after UL (Straka and Dieringer, 1995) suggests that a lesion-induced asymmetric vestibular tone might not be rebalanced in aquatic compared to terrestrial tetrapods. Accordingly, Xenopus frogs with their permanent aquatic life style, at variance with adult terrestrial amphibians such as grass frogs, should be unable to reestablish a normal posture after a unilateral peripheral vestibular nerve lesion that eliminates utricular signals.

Compatible with the latter prediction, larval and adult Xenopus, in which one labyrinth was surgically removed, develop a permanent postural asymmetry and asymmetric limb positions that remain uncompensated even several months after the lesion (Figure 9A; Lambert et al., 2009). Immediately after the surgery, Xenopus tadpoles exhibit a longitudinal torsion and a curvature of the body/tail toward the side of the lesion (Figure 9A) that is caused by a relatively weaker contraction of the axial body musculature on the intact side. The bending of the body/tail and the accompanying circling movements are caused by the removal of one utricle and persist throughout further development (Lambert et al., 2009). Moreover, after UL Xenopus larvae develop a hunchback body shape and markedly asymmetric limb positions, both of which are manifested during metamorphosis into adult frogs (Figure 9A). These young adult frogs exhibit a scoliotic postural syndrome with strong deformations of the spine and all vertebrae (Figure 9B). If the UL is performed early after metamorphosis in young adult frogs, the typical postural syndrome along with a severe perturbation of the locomotor pattern is observed as well, however, skeletal deformations are absent, although the behavioral asymmetries persist.

Quantification of the scoliotic syndrome elicited by the UL in Xenopus tadpoles indicated a complex pattern of postural deformations of the skeletal geometry (Lambert et al., 2009). Even though the extent of the spine curvature varies in the frontal plane between different animals, it is consistently directed toward the ipsilesional side, accompanied by a transverse rotation along the longitudinal body axis and a substantial deformation of the vertebrae (Figure 9B), closely resembling the overall structural deformations of human idiopathic scoliosis.
The development of skeletal asymmetries exclusively after a unilateral lesion of the utricle in Xenopus supports the notion that this vestibular endorgan plays a dominant role in the descending control of the tone of the axial musculature, the establishment of symmetric skeletal components and a symmetric body axis (Figure 9C) as shown in guinea pig (de Waele et al., 1989). In terrestrial tetrapods, sensory substitution of eliminated vestibular inputs and in particular an increased efficacy of proprioceptive signals is the dominant mechanism for postural recovery in frog (Dieringer, 1995) and likely also in humans (Brandt et al., 1997). As a consequence, any asymmetric activity in descending vestibuloand vestibulo-reticulo-spinal pathways after the lesion diminishes over a species-specific period. In contrast, in aquatic tetrapods such as larval and adult Xenopus, or to a certain extent water frogs (Figure 4A), an asymmetric tonic neuronal discharge is manifested, since a compensation of postural deficits is absent as indicated by the continuous rolling and circling movements of these animals during locomotion. This is most likely due to the water-floating aquatic life style and the virtual absence of gravitation-related limb proprioception in both larval and adult Xenopus. Thus, the lack of the latter sensory signals that could substitute for the impaired vestibular signals after UL prevents a recalibration of bilateral central activity with signals related to the ground-based reference frame thereby causing a permanent postural asymmetry.

The establishment of scoliotic skeletal deformations in the absence of "vestibular compensation" in larval Xenopus also emphasizes the importance of utricular signals beyond the classical role in gaze- and posture-stabilizing reflexes (Straka and Dieringer, 2004). Bilateral adequately adjusted descending utriculo-spinal signals might be responsible for the formation of a symmetric body blueprint during ontogeny. Any uncompensated, permanent asymmetry in vestibulo-spinal and vestibulo-reticulo-spinal circuits would cause a continuous imbalance of the driving force to spinal motoneurons and as a result a permanent tonic contraction of particular populations of axial and limb extensor and flexor muscles (Figure 9D). Such a bilateral asymmetry in muscle tension and pulling at individual joints and bones would progressively lead to deformations of the skeletal geometry, given that in Xenopus larvae, most skeletal elements are still cartilaginous and not, or only mildly ossified (Miura et al., 2008). The progressing ossification will then "fix" the skeletal elements in the deformed state during further development.

The direct causal relation between a unilateral vestibular loss and the development of scoliotic skeletal deformations in vertebrates under certain circumstances that are linked to the particular eco-physiology and anatomy of Xenopus is an important finding and helps to further elucidate the origin and mechanism of the clinical syndrome of adolescent idiopathic scoliosis in humans. This is due to the fact that the specific conditions under which the skeletal deformations were triggered in Xenopus are similar to those that occur during human gestation, when the first structural changes of this disease are implemented. Developing human embryos and newborn babies during the first year make rather limited use of limb proprioception that could serve as a substituting reference frame to recalibrate a naturally occurring vestibular imbalance (Assaiante et al., 2005). In addition, 
A

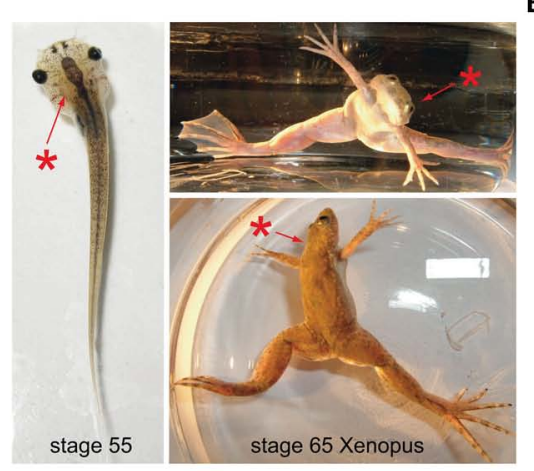

C

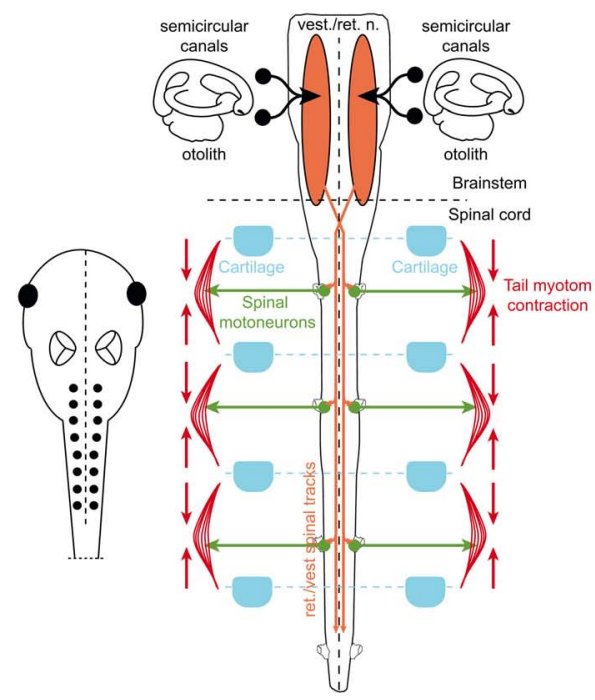

B

D
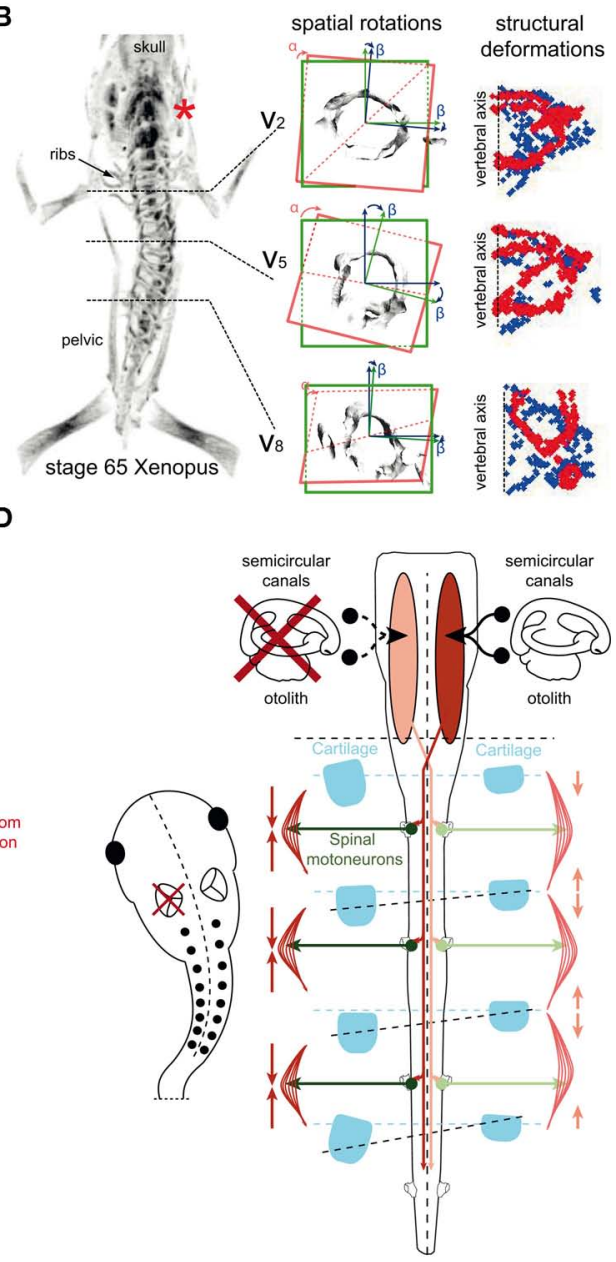

FIGURE 9 | Postural deficits and scoliotic deformations in adult Xenopus laevis after UL at larval stages. (A) Photographs of a stage 56 larval and a stage 65 young adult Xenopus frog after removal of the left labyrinth (red asterisks), respectively, illustrating the acute tail bending in the tadpole and the chronic postural asymmetry after metamorphosis in the adult. (B) 3D-reconstruction of a $\mu$-CT scan (left row) depicting the skeleton of a young adult Xenopus frog exposed to a UL (red asterisk) at larval stage 55;

cross-sections in the middle row show the spatial rotation of vertebra 2 (V2), 5 (V5), and 8 (V8) in the coronal (" $\alpha$ ") and medio-lateral (" $\beta$ ") plane; cross-sections in the right row show the structural deformation of $\mathrm{V} 2, \mathrm{~V} 5$, and $V 8$ as a function of the symmetry between left (red) and right (blue) hemi-vertebrae. (C,D) Presumed causality between a UL, development of a permanent postural asymmetry and skeletal deformation; the balanced/imbalanced bilateral activity in descending brainstem-spinal pathways, spinal motoneurons and axial musculature determines the skeletal symmetry in controls (C) and the deformation after permanent asymmetric contractions following UL on the left side (D). Modified and adapted from Lambert et al. (2009). skeletal elements during this period would also be relatively soft and prone to deformations by a constant asymmetric pull of the inserting muscles. Thus, different developmental stages of frogs, embryos - larvae - adults, offer convenient models for studying various aspects of lesion-induced plasticity after a loss of labyrinthine function. Further studies in amphibian models will not only reveal specific details of general reaction patterns of cellular and network properties in vertebrates, but will also illustrate the particular importance of bilateral adequate vestibular signaling for

\section{REFERENCES}

Ashcroft, D. W., and Hallpike, C. S. (1934). On the function of the saccule. J. Laryngol. 49, 450-458.
Assaiante, C., Mallau, S., Viel, S., Jover, M., and Schmitz, C. (2005). Development of postural control in healthy children: a functional

an appropriate assembly of the body blueprint during ontogeny (Straka, 2010).

\section{ACKNOWLEDGMENTS}

This project was supported by funds from the German Federal Ministry of Education and Research under the Grant code 01 EO 0901 and by a joint travel grant from the German Academic Exchange Service and the Norwegian Ministry of Science (Project-ID 50902500).

approach. Neural Plast. 12, 109-118.

Baird, R. A., and Lewis, E. R. (1986). Correspondences between afferent innervation patterns and response dynamics in the bullfrog utricle and lagena. Brain Res. 369, $48-64$. 
Beraneck, M., Hachemaoui, M., Idoux, E., Ris, L., Uno, A., Godaux, E., Vidal, P. P., Moore, L. E., and Vibert, N. (2003). Long-term plasticity of ipsilesional medial vestibular nucleus neurons after unilateral labyrinthectomy. J. Neurophysiol. 90, 184-203.

Beraneck, M., Idoux, E., Uno, A., Vidal, P. P., Moore, L. E., and Vibert, N. (2004). Unilateral labyrinthectomy modifies the membrane properties of contralesional vestibular neurons. J. Neurophysiol. 92, 1668-1684.

Beraneck, M., Pfanzelt, S., Vassias, I., Rohregger, M., Vibert, N., Vidal, P. P., Moore, L. E., and Straka, H. (2007). Differential intrinsic response dynamics determine synaptic signal processing in frog vestibular neurons. J. Neurosci. 27, 4283-4296.

Bergquist, F., Ludwig, M., and Dutia, M. B. (2008). Role of the commissural inhibitory system in vestibular compensation in the rat. J. Physiol. 586, 4441-4452.

Bernard, C., Cochran, S. L., and Precht, W. (1985). Presynaptic actions of cholinergic agents upon the hair cellafferent fiber synapse in the vestibular labyrinth of the frog. Brain Res. 338, 225-236.

Bienhold, H., Abeln, W., and Flohr, H. (1981). "Drug effects on vestibular compensation," in Lesion-Induced Neuronal Plasticity in Sensorimotor Systems, eds H. Flohr and W. Precht (Berlin/Heidelberg: Springer), 265-273.

Bienhold, H., and Flohr, H. (1980). Role of cholinergic synapses in vestibular compensation. Brain Res. 195, 476-478.

Blanks, R. H., and Precht, W. (1976). Functional characterization of primary vestibular afferents in the frog. Exp. Brain Res. 25, 369-390.

Brandt, T., Strupp, M., Arbusow, V., and Dieringer, N. (1997). Plasticity of the vestibular system: central compensation and sensory substitution for vestibular deficits. Adv. Neurol. 73, 297-309.

Caston, J., Precht, W., and Blanks, R. H. I. (1977). Response characteristics of frog's lagena afferents to natural stimulation. J. Comp. Physiol. A 118, 273-289.

Cochran, S. L., Kasik, P., and Precht, W. (1987). Pharmacological aspects of excitatory synaptic transmission to second-order vestibular neurons in the frog. Synapse 1, 102-123.

Cortopassi, K. A., and Lewis, E. R. (1996). High-frequency tuning properties of bullfrog lagenar vestibular afferent fibers. J. Vestib. Res. 6, 105-119.

Cullen, K. E., Minor, L. B., Beraneck, M., and Sadeghi, S. G. (2009). Neural substrates underlying vestibular compensation: contribution of peripheral versus central processing. J. Vestib. Res. 19, 171-182.

Curthoys, I. S. (2000). Vestibular compensation and substitution. Curr. Opin. Neurol. 13, 27-30.

Curthoys, I. S., and Halmagyi, G. M. (1999). Vestibular compensation. Adv. Otorhinolaryngol. 55, 82-110.

Darlington, C. L., Dutia, M. B., and Smith, P. F. (2002). The contribution of the intrinsic excitability of vestibular nucleus neurons to recovery from vestibular damage. Eur. J. Neurosci. 15, 1719-1727.

Darlington, C. L., and Smith, P. F. (2000). Molecular mechanisms of recovery from vestibular damage in mammals: recent advances. Prog. Neurobiol. 62, 313-325.

de Burlet, H. M. (1929). Zur vergleichenden Anatomie der Labyrinthinnervation. J. Comp. Neurol. 47, 155-169.

de Kleijn, A. (1914). Zur Analyse der Folgezustände einseitiger Labyrinthexstirpation beim Frosch. Pflügers Arch. 159, 218-223.

de Waele, C., Graf, W., Josset, P., and Vidal, P. P. (1989). A radiological analysis of the postural syndromes following hemilabyrinthectomy and selective canal and otolith lesions in the guinea pig. Exp. Brain Res. 77, 166-182.

Dieringer, N. (1988). Immediate saccadic substitution for deficits in dynamic vestibular reflexes of frogs with selective peripheral lesions. Prog. Brain Res. 76, 403-409.

Dieringer, N. (1995). 'Vestibular compensation': neural plasticity and its relations to functional recovery after labyrinthine lesions in frogs and other vertebrates. Prog. Neurobiol. 46, 97-129.

Dieringer, N. (2003). Activity-related postlesional vestibular reorganization. Ann. N. Y. Acad. Sci. 1004, 50-60.

Dieringer, N., Künzle, H., and Precht, W. (1984). Increased projection of ascending dorsal root fibers to vestibular nuclei after hemilabyrinthectomy in the frog. Exp. Brain Res. 1984, 574-578.

Dieringer, N., and Precht, W. (1977). Modification of synaptic input following unilateral labyrinthectomy. Nature 269, 431-433.

Dieringer, N., and Precht, W. (1979a). Mechanisms of compensation for vestibular deficits in the frog. I. Modification of the excitatory commissural system. Exp. Brain Res. 36, 311-328.

Dieringer, N., and Precht, W. (1979b). Mechanisms of compensation for vestibular deficits in the frog. II. Modification of the inhibitory pathways. Exp. Brain Res. 36, 329-357.

Dieringer, N., and Precht, W. (1981). "Functional restitution of static and dynamic reflexes in the frog after hemilabyrinthectomy," in LesionInduced Neuronal Plasticity in Sensorimotor Systems, eds H. Flohr and W. Precht (Berlin: Springer), 184-196.

Dieringer, N., and Precht, W. (1982). Compensatory head and eye movements in the frog and their contribution to stabilization of gaze. Exp. Brain Res. 47, 394-406.

Dunn, R. F. (1978). Nerve fibers of the eighth nerve and their distribution to the sensory nerves of the inner ear in the bullfrog. J. Comp. Neurol. 182, 621-636.

Dutia, M. B. (2010). Mechanisms of vestibular compensation: recent advances. Curr. Opin. Otolaryngol. Head Neck Surg. 18, 420-424.

Ewald, J. R. (1892). Physiologische Untersuchungen über das Endorgan des $N$. oktavus. Wiesbaden: Bergmann.

Flohr, H., Abeln, W., and Lüneburg, U. (1985). Neurotransmitter and neuromodulator systems involved in vestibular compensation. $\mathrm{Rev}$. Oculomot. Res. 1, 269-277.

Flohr, H., Bienhold, H., Abeln, W., and Macskovics, I. (1981). "Concepts of vestibular compensation," in Lesion-Induced Neuronal Plasticity in Sensorimotor Systems, eds. H. Flohr and W. Precht (Berlin/Heidelberg: Springer), 153-172.

Flohr, H., Burt, A., Will, U., and Ammelburg, R. (1989). "Vestibular compensation: a paradigm for lesioninduced neural plasticity," in Fundamentals of Memory Formation: Neuronal Plasticity, and Brain Function, ed. H. Rahmann (Stuttgart: Fischer), 243-260.

Flohr, H., and Lüneburg, U. (1993). Role of NMDA receptors in lesioninduced plasticity. Arch. Ital. Biol. 131, 173-190.

Gacek, R. R., and Schoonmaker, J. E. (1997). Morphologic changes in the vestibular nerves and nuclei after labyrinthectomy in the cat: a case for the neurotrophin hypothesis in vestibular compensation. Acta Otolaryngol. 117, 244-249.

Gallé, H., and Clemens, A. (1973). The sacculus of Rana: an equilibrium organ. Int. J. Equilib. Res. 3, 33-47.
Gamkrelidze, G., Giaume, C., and Peusner, K. D. (1998). The differential expression of low-threshold sustained potassium current contributes to the distinct firing patterns in embryonic central vestibular neurons. J. Neurosci. 18, 1449-1464.

Gamkrelidze, G., Giaume, C., and Peusner, K. D. (2000). Firing properties and dendrotoxin-sensitive sustained potassium current in vestibular nuclei neurons of the hatchling chick. Exp. Brain Res. 134, 398-401.

Goltz, F. (1870). Ueber die physiologische Bedeutung der Bogengänge des Ohrlabyrinths. Pflügers Arch. 3, 172-192.

Goto, F., Meng, H., Bai, R., Sato, H., Imagawa, M., Sasaki, M., and Uchino, Y. (2003). Eye movements evoked by the selective stimulation of the utricular nerve in cats. Auris Nasus Larynx 30, 341-348.

Goto, F., Straka, H., and Dieringer, N. (2000). Expansion of afferent vestibular signals after the section of one of the vestibular nerve branches. J. Neurophysiol. 84, 581-584.

Goto, F., Straka, H., and Dieringer, N. (2001). Postlesional vestibular reorganization in frogs: evidence for a basic reaction pattern after nerve injury. J. Neurophysiol. 85, 2643-2646.

Goto, F., Straka, H., and Dieringer, N. (2002). Gradual and reversible central vestibular reorganization in frog after selective labyrinthine nerve branch lesions. Exp. Brain Res. 147, 374-386.

Graf, W., de Waele, C., and Vidal, P. P. (1995). Functional anatomy of the head-neck movement system of quadrupedal and bipedal mammals. J. Anat. 186, 55-74.

Graham, B. P., and Dutia, M. B. (2001). Cellular basis of vestibular compensation: analysis and modelling of the role of the commissural inhibitory system. Exp. Brain Res. 137, 387-396. Gribenski, A. (1963). Contribution à l'étude fonctionnelle des canaux semi-circulaires chez la grenouille (Rana esculenta). J. Physiol. (Paris) 55(Suppl. VII), 1-95.

Hamann, K. F., Reber, A., Hess, B. J., and Dieringer, N. (1998). Longterm deficits in otolith, canal and optokinetic ocular reflexes of pigmented rats after unilateral vestibular nerve section. Exp. Brain Res. 118 , 331-340.

Haque, A., Zakir, M., and Dickman, J. D. (2008). Recovery of gaze stability during vestibular regeneration. $J$. Neurophysiol. 99, 853-865. 
Harada, Y., Kasuga, S., and Tamura, S. (2001). Comparison and evolution of the lagena in various animal species. Acta Otolaryngol. 121, 355-363.

Hernandez, J. D., Hoffman, L. F., and Honrubia, V. (1998). Vestibular nerve regeneration in the bullfrog, Rana catesbeiana: peripheral dendrites. Otolaryngol. Head Neck Surg. 119, 244-254.

Holler, S., and Straka, H. (2001). Plane-specific brainstem commissural inhibition in frog second-order semicircular canal neurons. Exp. Brain Res. 137, 190-196.

Honrubia, V., Hoffman, L. F., Sitko, S., and Schwartz, I. R. (1989). Anatomic and physiological correlates in bullfrog vestibular nerve. J. Neurophysiol. 61, 688-701.

Jørgensen, M. B., and ChristensenDalsgaard, J. (1991). Peripheral origins and functional characteristics of vibration-sensitive VIIIth nerve fibers in the frog Rana temporaria. J. Comp. Physiol. 169, 341-347.

Kaas, J. H. (2000). The reorganization of somatosensory and motor cortex after peripheral nerve or spinal cord injury in primates. Prog. Brain Res. 128, 173-179.

Kasahara, M., and Uchino, Y. (1971). Selective mode of commissural inhibition induced by semicircular canal afferents on secondary vestibular neurones in the cat. Brain Res. 34, 366-369.

Kasik, P., Cochran, S. L., Dieringer, N., and Precht, W. (1986). Evidence for an alteration in brainstem cholinergic pathways following unilateral labyrinthectomy in the frog. Brain Res. 363, 188-191.

Kitahara, T., Takeda, N., Emson, P. C., Kubo, T., and Kiyama, $\mathrm{H}$. (1997). Changes in nitric oxide synthase-like immunoreactivities in unipolar brush cells in the rat cerebellar flocculus after unilateral labyrinthectomy. Brain Res. 765, 1-6.

Knöpfel, T., and Dieringer, N. (1988). Lesion-induced vestibular plasticity in the frog: are $N$-methyl-Daspartate receptors involved? Exp. Brain Res. 72, 129-134.

Knöpfel, T. (1987). Evidence for $N$ methyl-D-aspartic acid receptormediated modulation of the commissural input to central vestibular neurons of the frog. Brain Res. 24, 212-224.

Kolb, E. (1955). Untersuchungen über zentrale Kompensation und Kompensationsbewegungen einseitig entstateter Frösche. Z. Vgl. Physiol. 37, 136-160.

Koyama, H., Lewis, E. R., Leverenz, E. L., and Baird, R. A. (1982). Acute seismic sensitivity in the bullfrog ear. Brain Res. 250, 168-172.

Kunkel, A., and Dieringer, N. (1994). Morphological and electrophysiological consequences of unilateral pre- versus postganglionic vestibular lesions in the frog. J. Comp. Physiol. A 174, 621-632.

Lambert, F. M., Malinvaud, D., Glaunès, J., Bergot, C., Straka, H., and Vidal, P. P. (2009). Vestibular asymmetry as the cause of idiopathic scoliosis: a possible answer from Xenopus. J. Neurosci. 29, 12477-12483.

Lannou, J., and Cazin, L. (1976). Responses to tilting of fibers of the frog's saccular nerve. Pflügers Arch. 366, 143-146.

Laudenbach, J. (1899). Zur otolithenfrage. Pflügers Arch. 77, 311-320.

Lewis, E. R., and Li, C. W. (1975). Hair cell types and distributions in the otolithic and auditory organs of the bullfrog. Brain Res. 83, 35-50.

Llinás, R., and Walton, K. (1979). "Vestibular compensation: a distributed property of the central nervous system," in Integration in the Nervous System, eds H. Asanuma and V. J. Wilson (Tokyo: Igaku Shoin), 145-166.

MacNaughton, I. P., and McNally W. J. (1946). Some experiments which indicate that the frog's lagena has an equilibrial function. J. Laryngol. Otol. 61, 204-214.

Malinvaud, D., Vassias, I., Reichenberger, I., Rössert, C., and Straka, H. (2010). Functional organization of vestibular commissural connections in frog. J. Neurosci. 30, 3310-3325.

McNally, W. J., and Tait, J. (1925). Ablation experiments on the labyrinth of the frog. Am. J. Physiol. 75, 155-174.

McNally, W. J., and Tait, J. (1933). Some results of section of particular nerve branches to the ampullae of the four vertical semicircular canals of the frog. Q. J. Exp. Physiol. 23, 147-196.

Miura, S., Hanaoka, K., and Togashi, S. (2008). Skeletogenesis in Xenopus tropicalis: characteristic bone development in an anuran amphibian. Bone 43, 901-909.

Newman, A., and Honrubia, V. (1992). Regeneration of the eighth cranial nerve in the bullfrog, Rana catesbeiana. Exp. Neurol. 115, 115-120.

Newman, A., Honrubia, V., and Bell, T. (1987). Regeneration of the eighth cranial nerve. II. Physiologic verification in the bullfrog. Laryngoscope 97, 1219-1232.

Newman, A., Kuruvilla, A., Pereda, A., and Honrubia, V. (1986). Regeneration of the eight cranial nerve. I. Anatomic verification in the bullfrog. Laryngoscope 96, 484-493.

Olabi, B., Bergquist, F., and Dutia, M. B. (2009). Rebalancing the commissural system: mechanisms of vestibular compensation. J. Vestib. Res. 19, 201-207.

Ozawa, S., Precht, W., and Shimazu, H. (1974). Crossed effects on central vestibular neurons in the horizontal canal system of the frog. Exp. Brain Res. 19, 394-405.

Precht, W., and Dieringer, N. (1985). Neuronal events paralleling functional recovery (compensation) following peripheral vestibular lesions. Rev. Oculomot. Res. 1, 251-268.

Precht, W., Shimazu, H., and Markham, C. H. (1966). A mechanism of central compensation of vestibular function following hemilabyrinthectomy. J. Neurophysiol. 29, 996-1010.

Ramprashad, F., Landolt, J. P., Money, K. E., and Laufer, J. (1986). Comparative morphometric study of the vestibular system of the vertebrata: reptilia, aves, amphibia, and pisces. Acta Otolaryngol. Suppl. 427, $1-42$.

Rohregger, M., and Dieringer, N. (2002). Principles of linear and angular vestibuloocular reflex organization in the frog. J. Neurophysiol. 87, 385-398.

Rohregger, M., and Dieringer, N. (2003). Postlesional vestibular reorganization improves the gain but impairs the spatial tuning of the maculoocular reflex in frogs. J. Neurophysiol. 90, 3736-3749.

Rossi, M. L., Prigioni, I., Valli, P., and Casella, C. (1980). Activation of the efferent system in the isolated frog labyrinth: effects on the afferent EPSPs and spike discharge recorded from single fibres of the posterior nerve. Brain Res. 3, 125-137.

Schuhknecht, H. (1982). Behavior of the vestibular nerve following labyrinthectomy. Ann. Otol. Rhinol. Laryngol. 91, 16-32.

Shao, M., Hirsch, J. C., and Peusner, K. D. (2012). Plasticity of spontaneous excitatory and inhibitory synaptic activity in morphologically defined vestibular nuclei neurons during early vestibular compensation. J. Neurophysiol. 107, 29-41.

Shao, M., Popratiloff, A., Yi, J., Lerner, A., Hirsch, J. C., and Peusner, K. D. (2009). Adaptation of chicken vestibular nucleus neurons to unilateral vestibular ganglionectomy. $\mathrm{Neu}$ roscience 21, 988-1007.

Shimazu, H. (1972). Organization of the commissural connections: physiology. Prog. Brain Res. 37, 177-190.

Smith, P. F., and Curthoys, I. S. (1989). Mechanisms of recovery following unilateral labyrinthectomy: a review. Brain Res. Rev. 14 155-180.

Smith, P. F., and Darlington, C. L. (1997). The contribution of $N$-methyl-D-aspartate receptors to lesion-induced plasticity in the vestibular nucleus. Prog. Neurobiol. 53, 517-531.

Smith, P. F., Geddes, L. H., Baek, J. H., Darlington, C. L., and Zheng, Y. (2010). Modulation of memory by vestibular lesions and galvanic vestibular stimulation. Front. Neurol. 1:141. doi:10.3389/fneur.2010.00141

Sperry, R. W. (1945). The problem of central nervous reorganization after nerve regeneration and muscle transposition. Q. Rev. Biol. 20, 311-369.

Straka, H., Baker, R., and Gilland, E. (2001). Rhombomeric organization of vestibular pathways in larval frogs. J. Comp. Neurol. 437, 42-55.

Straka, H., Beraneck, M., Rohregger, M., Moore, L. E., Vidal, P. P., and Vibert, N. (2004). Second-order vestibular neurons form separate populations with different membrane and discharge properties. J. Neurophysiol. 92, 845-861.

Straka, H., and Dieringer, N. (1995). Spinal plasticity after hemilabyrinthectomy and its relation to postural recovery in the frog. $J$. Neurophysiol. 73, 1617-1631.

Straka, H., and Dieringer, N. (2004). Basic organization principles of the VOR: lessons from frogs. Prog. $\mathrm{Neu}$ robiol. 73, 259-309.

Straka, H., Holler, S., and Goto, F. (2002). Patterns of canal and otolith afferent input convergence in frog second order vestibular neurons. $J$. Neurophysiol. 88, 2287-2301.

Straka, H., Holler, S., Goto, F., Kolb, F. P., and Gilland, E. (2003). Differential spatial organization of otolith signals in frog vestibular nuclei. $J$. Neurophysiol. 90, 3501-3512.

Straka, H., Kunkel, A., and Dieringer, N. (1993). Spinal compensation for postural deficits after hemilabyrinthectomy? Neuroreport 4, 1071-1074.

Straka, H., Vibert, N., Vidal, P. P., Moore, L. E., and Dutia, M. B. 
(2005). Intrinsic properties of vertebrate vestibular neurons: function, development and plasticity. Prog. Neurobiol. 76, 349-392.

Straka H. (2010). Ontogenetic rules and constraints of vestibulo-ocular reflex development. Curr. Opin. Neurobiol. 20, 689-695.

Tait, J., and McNally, W. J. (1934). Some features of the action of the utricular maculae (and of the associated action of the semicircular canals) of the frog. Philos. Trans. R. Soc. Lond. B Biol. Sci. 224, 241-268.

Thauer, R., and Peters, G. (1935). Der Einflußoperativer und pharmakologischer Eingriffe am Labyrinth auf Körperhaltung und Bewegung. Pflügers Arch. 235, 316-329.
Tighilet, B., Brezun, J. M., Sylvie, G. D., Gaubert, C., and Lacour, M. (2007). New neurons in the vestibular nuclei complex after unilateral vestibular neurectomy in the adult cat. Eur. J. Neurosci. 1, 47-58.

Vibert, N., Babalian, A., Serafin, M. Gasc, J. P., Mühlethaler, M., and Vidal, P. P. (1999). Plastic changes underlying vestibular compensation in the guinea-pig persist in isolated, in vitro whole brain preparations. Neuroscience 93, 413-432.

Vibert, N., de Waele, C., Serafin, M., Babalian, A., Mühlethaler, M., and Vidal, P. P. (1997). The vestibular system as a model of sensorimotor transformations. A combined in vivo and in vitro approach to study the cellular mechanisms of gaze and posture stabilization in mammals. Prog. Neurobiol. 51, 243-286.

Vidal, P. P., de Waele, C., Vibert, N., and Mühlethaler M. (1998). Vestibular compensation revisited. Otolaryngol. Head Neck Surg. 19, 34-42.

von Bechterew, W. (1883). Ergebnisse der Durchschneidung des N. acusticus nebst Erörterung der Bedeutung der semicirculären Kanäle für das Körpergleichgewicht. Pflügers Arch. Gesamte. Physiol. 30, 312-347.

Conflict of Interest Statement: The authors declare that the research was conducted in the absence of any commercial or financial relationships that could be construed as a potential conflict of interest.
Received: 22 November 2011; paper pending published: 21 December 2011; accepted: 05 March 2012; published online: 03 April 2012.

Citation: Lambert FM and Straka $H$ (2012) The frog vestibular system as a model for lesion-induced plasticity: basic neural principles and implications for posture control. Front. Neur. 3:42. doi 10.3389/fneur.2012.00042

This article was submitted to Frontiers in Neuro-otology, a specialty of Frontiers in Neurology.

Copyright (c) 2012 Lambert and Straka. This is an open-access article distributed under the terms of the Creative Commons Attribution Non Commercial License, which permits non-commercial use, distribution, and reproduction in other forums, provided the original authors and source are credited. 